\title{
River-to-Sea Pressure Retarded Osmosis: Resource Utilization in a Full-Scale Facility
}

\author{
Galen O’Toole ${ }^{1}$, Lori Jones ${ }^{1}$, Chris Coutinho ${ }^{1,2}$, Corey Hayes ${ }^{1}$, Monica Napoles ${ }^{1}$, and Andrea Achilli ${ }^{1, *}$ \\ ${ }^{1}$ Environmental Resources Engineering Department, Humboldt State University, Arcata, CA 95521, USA \\ ${ }^{2}$ REDstack BV, 8606 JR Sneek, The Netherlands \\ * Corresponding author. Tel.: +1 707 826-3608, fax: +1 707 826-3616, e-mail address: \\ aa2767@humboldt.edu
}

\begin{abstract}
Pressure retarded osmosis (PRO) is a technology that can be utilized to recover energy from the mixing of freshwater with seawater. This source of renewable energy is sizeable and in the past decade several investigations analyzed its potential. The vast majority of studies focused on mass transfer problems across the membrane in order to improve membrane productivity and just recently studies started to look at membrane module efficiencies and parasitic loads within the PRO facility. In this article, the net specific energy production from a facility-scale PRO system was determined and optimized by using a novel simulation method that integrates parasitic loads and efficiencies of the PRO facility components and combines the model with an optimization software in a linked system optimization scheme. It was found that the overall net specific energy that may be recovered by a river-to-sea PRO facility is approximately $0.12 \mathrm{kWh}$ per $\mathrm{m}^{3}$ of permeate. Furthermore, a sensitivity analysis was performed to elucidate the relationship between net specific energy and power density as functions of membrane area, flow rates, and operating pressures. In general, in order to maximize resource recovery, a low power density, thus a low membrane productivity, must be accepted.
\end{abstract}

Keywords: Renewable Energy, Salinity Gradient Power, Pressure Retarded Osmosis, Net Specific Energy, Power Density, Facility Analysis. 


\section{Introduction}

The United Nations Framework Convention on Climate Change (UNFCCC) heavily focuses on stabilizing greenhouse gas (GHG) emissions in order to mitigate climate change; these emissions goals are often aimed at the carbon-intensive energy sector [1]. Adding renewable energy technologies to the global energy portfolio is paramount to stabilizing GHG emissions. A renewable energy source of recent interest is naturally occurring salinity gradients. The chemical energy of mixing available at the interface between freshwater and seawater, such as when a river meets an ocean, is comparable to a waterfall 225 m high [2]. The global potential for salinity gradient power has been estimated to be 1,650 TWh/year [3], approximately 9\% of the current global renewable energy production [4]. Pressure retarded osmosis (PRO) is a technology that can harness work from salinity gradients by transforming the osmotic pressure between the two solutions into mechanical work [5]. The solution of higher salinity (e.g., seawater) is pressurized to some point below its osmotic pressure so that water flows from the solution of lower salinity (e.g., river water) across a semipermeable membrane [6]. Work is harnessed by diverting a portion of the pressurized high salinity solution to a turbine at a rate equal to the flow rate through the membrane.

Quantifying the specific energy available from the mixing between river water and seawater begins with the Gibbs free energy of mixing two solutions with different ionic strengths. Assuming a reversible PRO process, in which an infinitesimal amount of fresh water is mixed in an infinite amount of seawater, the ideal work per unit volume of fresh water is the Gibbs free energy of mixing, given by [7]:

$$
\frac{W_{\text {ideal }}}{i R T}=\frac{c_{\text {final }}}{\phi} \ln c_{\text {final }}-c_{f} \ln c_{f}-\frac{(1-\phi)}{\phi} c_{d} \ln c_{d}
$$

Equation 1

Where $c_{\text {final }}, c_{f}$, and $c_{d}$ represent the concentrations of the final, initial feed, and initial draw solutions, respectively. The Van 't Hoff factor is given by $i, R$ is the universal gas constant, and $T$ is the temperature. 
The ratio of the volume of the initial feed solution to the initial volume of both the feed and draw solutions is given by $\phi$. For a river-to-sea PRO system, at a temperature of $291 \mathrm{~K}$, the maximum specific energy available is approximately $0.72 \mathrm{kWh}$ per $\mathrm{m}^{3}$ of water permeate through the membrane. The maximum specific energy occurs when the volume of feed water tends to zero [7]. In practice, the achieved specific energy of the permeate flow will always be less than the theoretical specific energy due to entropy and system inefficiencies [8].

To date, the overwhelming majority of PRO investigations have focused on the mass transfer mechanisms in bench scale PRO systems, which usually consist of a small, flat sheet membrane coupon. Yip and coworkers modeled PRO at a constant pressure and accounted for non-ideal effects within the membrane module: concentration polarization, system friction losses, uncontrolled mixing losses, and unutilized energy [9]. This study found that the PRO process can recover approximately 55\% of the Gibbs free energy of mixing. However, the PRO model only accounted for the inefficiencies internal to a membrane module with co-current flow while commercially available membrane modules consist of spiral-wound membrane envelopes, which always operate in a cross-flow configuration [10].

The typical rubric for evaluating the performance of PRO systems has been power density: the power output per unit membrane area $\left(\mathrm{W} / \mathrm{m}^{2}\right)[3,11-14]$. Power density is primarily an evaluation of the membrane productivity and it is usually determined via bench-scale experiments. The benchmark for commercial PRO was set at $5 \mathrm{~W} / \mathrm{m}^{2}$, which was determined by the Norwegian power company Statkraft, during their extensive demonstration-scale investigation [11].

Straub and coworkers performed a theoretical module-scale PRO evaluation of power density and power output [15]. They reported that for fixed flow rates along the membrane module and increasing membrane area, power output increases while power density decreases. This inverse relationship between power generation and power density implies that achieving greater power output results in a lower membrane power density. Their investigation suggests that the power density of a membrane is not a metric that is directly correlated with the power output of a PRO module. This investigation also did not consider 
external system inefficiencies, which will work to greatly reduce the overall power output. Kim and coworkers performed an experimental analysis with a prototype 8040 PRO membrane module [16]. Their investigation carefully examined the relationships between pressures, flow rates, and salinity gradients in the spiral wound module. They concluded that the flow resistance and shadow effect of the spacers used within the feed channel caused a reduction in the net energy generation of the spiral wound membrane module. They showed, qualitatively, that pressure losses in the feed channel require higher inlet feed pressure to the module, thereby requiring increased inlet pressure on the draw solution to maintain the desired pressure difference across the membrane. Furthermore, the pressure losses through the test module exceeded model predictions, largely due to dense tricot fabric spacers necessary to prevent membrane deformation. Overall, the high experimental pressure losses in the feed channel significantly reduce the efficiency of the spiral-wound module.

The energy lost in processes internal to the PRO module was further elaborated by Achilli and coworkers who recorded experimental data from a physical PRO system using a 4040 spiral wound membrane module [17]. This investigation showed that with higher cross flow velocities, power densities above 8 $\mathrm{W} / \mathrm{m}^{2}$ could be achieved; however, they showed that by accounting for the pumping energy required to overcome the pressure losses along the module, the increased cross flow velocities resulted in negative overall net specific energy. Thus, this study demonstrated that focusing on increasing the PRO membrane power density may not be a useful metric for estimating the potential of the PRO process to convert osmotic pressure to useful energy. This also indicated the importance of examining the specific energy of the process with inclusion of system inefficiencies within the PRO module.

As the next step in analyzing the available extractable energy in the PRO mixing process, this study looks at river-to-sea PRO from a facility perspective, including estimation of the energy requirements and losses in the water intakes and conveyance, fresh and seawater pretreatment, turbines, generators, and pressure exchangers. For this study, a model facility with a total capacity (freshwater plus seawater) of 30 MGD was considered. When evaluating PRO at the facility scale, the power produced is weighed against 
the energy costs of the key input resources: membranes, freshwater and saltwater. Post and coworkers suggest that the power density calculation must include equipment efficiencies and pretreatment energy costs for facility-scale assessment [18]. The concept of net power density, developed by Maisonneuve and coworkers, incorporates the energy losses of a PRO facility [13]. Net power density is a useful metric for maximizing the utility of the PRO membranes and relates the efficiency of the process to the quantity of membrane used, rather than to the limiting resource, the fresh water. The energy efficiency of the fresh water resource can be calculated from the specific energy, the energy generated from a unit volume of permeated fresh water [14]. Combining the concepts of net power and specific energy yields net specific energy, the useful work extracted from a unit volume of permeated fresh water. Net specific energy accounts for non-idealities of the PRO module and the energy lost in pumping, pretreatment and equipment efficiencies.

The objective of the current study is to determine the net specific energy production, and therefore the technical feasibility, of a river-to-sea PRO facility by accounting for energy expenditures and efficiencies from intake to outfall. The PRO facility is divided into five main subsystems: membrane module, freshwater and seawater pretreatment and conveyance, hydroturbine and generator, and pressure exchanger. Each subsystem is investigated to find energy consumption and production based on existing state-of-the-art technologies. The net specific energy production of the PRO facility is calculated by joining the subsystem energy requirements and a one-dimensional simulation model of a PRO module with an optimization software to construct a linked system optimization (LSO). The final outputs from the LSO are the maximum recoverable energy for the facility and optimal flow rates, pressures, module channel heights and number of modules. Furthermore, a sensitivity analysis was performed to elucidate the relationship between net specific energy and power density as functions of membrane area, flow rates, and operating pressures. 


\section{Materials \& Methods}

\subsection{Facility-Scale Simulation}

A typical PRO facility can be energetically characterized by examining five separate subsystems: PRO membrane modules, freshwater intake and pretreatment, saltwater intake and pretreatment, turbine and generator, and the pressure exchanger (Figure 1). A facility analysis approach begins with the power generated from the PRO membrane modules. To quantify the net specific energy of a PRO facility, a onedimensional non-ideal PRO simulation model was developed to approximate a spiral-wound membrane module. Non-idealities of the mass transport across the membrane exist within the PRO process, reducing the capacity of extractable work. Salt flux, which flows in the reverse direction of the water flux, significantly decreases the osmotic pressure across the membrane, thus ultimately reducing the energy recovery potential [6]. Additionally, the transport phenomenon known as concentration polarization works to decrease the effective water flux across the membrane and depress the optimum operating pressure [19, 20]. Parasitic loads such as intake pumping and pretreatment requirements further reduce the facility's power generation potential. Inherent in pumping costs are pump efficiencies and the pressure drops through pipes and appurtenances. The seawater and fresh water inputs both require treatment to the level of microfiltration (MF) or ultrafiltration (UF) prior to entering the PRO system [21]. Freshwater pretreatment is an especially important consideration in the PRO process because the water flows into the porous support layer of the membrane; fouling rates and biological growth in the support layer are likely to cause faster membrane degradation [22]. In the energy-capturing portion of the facility, the turbine, generator, and pressure exchanger have non-ideal efficiencies that also reduce the extractable work of the PRO process.

Figure 1 
Net specific energy $\left(\mathrm{SE}_{\mathrm{net}}\right)$ is the net power produced by the facility normalized to the permeate flow rate, given by:

$$
S E_{n e t}=\frac{Q_{p} \Delta P-P_{\text {parasitic }}}{Q_{p}}
$$

Equation 2

where $Q_{p}$ is the permeate flow rate across the membrane, $\Delta P$ is the hydraulic pressure of the solution entering the turbine, and $P_{\text {parasitic }}$ is the power of the parasitic loads and efficiency losses external to the PRO module: freshwater pretreatment and conveyance, seawater pretreatment and conveyance, and the efficiencies of the turbine, generator, and pressure exchanger.

\subsubsection{Membrane Module and Flow Configurations}

\subsubsection{Module Geometry}

The simulation model approximates the geometry of a spiral wound membrane module and estimates the flux of water and salt through the membrane. The key parameters for commercial PRO modules are module flow rates, module pressures, membrane baffling, spacer geometries, and the quantity of leaves per module. To translate this three-dimensional transport problem to a sequential solution using a 1dimensional model, an approximation of the module domain and assumptions about the flow through the module must be made.

The most common membrane modules used in large-scale RO applications are spiral-wound; multiple membrane leaves are attached to an inner perforated tube through which the permeate flows out. Thin, net-type spacers separate the leaves to create a channel through which water can flow. Spiral-wound modules used for PRO are configured similarly to forward osmosis (FO) modules: the flows of the solutions are cross current. In the PRO configuration, the feed solution enters the permeate tube, spirals out from the central perforated tube on the inside of the envelope, and then returns (Figure 2a) while the draw solution flows between the membrane leaves. One or more baffles are placed inside the membrane leaves to lengthen the feed flow path and promote turbulence, creating a tradeoff between increasing flux 
and increasing pressure loss along the membrane module. The draw solution flows in a horizontal manner past the membrane leaves (Figure 2b), which results in the solutions having a cross-flow configuration. The simulation model approximates the cross-flow configuration by modeling the feed flow path as shown in Figure 2c and the draw flow path as shown in Figure 2b.

Figure 2

\subsubsection{Module Discretization}

The flow rates, concentrations, and pressures within the membrane module must be solved at discrete points along the flow paths of both the feed and draw channels. Each discrete point represents a differential length of the flow path and corresponds with a specific area of membrane (Figure 3a) and volume of the feed and draw channels (Figure 3b).

Figure 3

The water flux, salt flux, and pressure loss are solved at each differential length, which allows for the determination of the exiting flow rates, concentrations, and pressures, which are used as the entering conditions for the next membrane differential length (Figure 3). These governing update equations are given by the following set of equations [8]:

$$
\begin{array}{ll}
Q_{D S, \text { out }}=Q_{D S, \text { in }}+J_{w} A_{\text {inc }} & \text { Equation 3 } \\
Q_{F S, \text { out }}=Q_{F S, \text { in }}-J_{w} A_{\text {inc }} & \text { Equation 4 } \\
C_{D S, \text { out }}=\frac{Q_{D S, \text { in }} C_{D S, \text { in }}-J_{S} A_{\text {inc }}}{Q_{D S, \text { in }}+J_{w} A_{\text {inc }}} & \text { Equation 5 } \\
C_{F S, \text { out }}=\frac{Q_{F S, \text { in }} C_{F S, \text { in }}+J_{S} A_{\text {inc }}}{Q_{F S, \text { in }}-J_{w} A_{\text {inc }}} & \text { Equation 6 } \\
P_{D S, \text { out }}=P_{D S, \text { in }}-P_{D S, \text { loss }} & \text { Equation 7 } \\
P_{F S, \text { out }}=P_{F S, \text { in }}-P_{F S, \text { loss }} & \text { Equation 8 }
\end{array}
$$


where the subscripts $F S$,in, FS, out, $D S$,in, and DS,out refer to the entering and exiting feed solution and the entering and exiting draw solution, respectively. $\mathrm{Q}$ is the flow rate, $\mathrm{C}$ is the concentration, and $\mathrm{P}$ is pressure. $A_{\text {inc }}$ is the differential area at each discretized step of the model. The $P_{\text {loss }}$ terms are the pressure drops due to friction at each step in each channel. These pressure drops are given by:

$$
P_{\text {loss }}=\frac{\lambda \rho v^{2} L}{2 d_{h}}
$$

Equation 9

where $\lambda$ is the friction coefficient, $\rho$ is the density of the fluid, $v$ is the velocity of the fluid, $L$ is the length of the channel, and $\mathrm{d}_{\mathrm{h}}$ is the hydraulic diameter of the channel. $J_{w}$ is the water flux across the PRO membrane, given by [5]:

$$
J_{w}=A(\Delta \pi-\Delta P)
$$

Equation 10

Where $\mathrm{A}$ is the water permeability coefficient of the membrane, $\Delta \pi$ is the osmotic pressure difference of the two solutions across the active layer of the membrane (Figure 4), and $\Delta \mathrm{P}$ is the applied hydraulic pressure. As the osmotic process is dependent on the temperature of the solutions, this investigation assumes $291 \mathrm{~K}$ for all calculations. The water will permeate across the membrane from the less concentrated feed channel to the more concentrated draw channel. As the membranes are not completely resistant to solute passage, some solute will permeate across the membrane in the opposite direction of the water flux. The solute flux across the membrane, referred to as $\mathrm{J}_{\mathrm{S}}$, is given by Fick's Law:

$$
J_{s}=B \Delta C
$$

Equation 11

Where $\mathrm{B}$ is the solute permeability coefficient of the membrane and $\Delta \mathrm{C}$ is the concentration difference across the active layer of the membrane (Figure 4). Fresh water flows through the membrane from the porous support to the active layer. A boundary layer forms at the interface between the draw solution and the active layer. In this boundary layer, dilutive external concentration polarization (ECP) is present due 
to water passing from the feed into the draw solution. Dilutive ECP works to reduce the effective concentration at the membrane surface. Within the porous support of the membrane, concentrative internal concentration polarization (ICP) is present. Salt accumulates in the porous support, and concentrative ICP works to increase the concentration at the membrane surface. Thus, the effective $\Delta \mathrm{C}$ is reduced to $C_{D, m}-C_{F, m}$ from the expected $C_{D, b}-C_{F, b}$ (Figure 4).

Figure 4

At steady state, the diffusive and convective transport of solute across the membrane must be balanced with the solute flux, given by [6]:

$$
D \frac{\partial C(x)}{\partial x}-J_{W} C(x)=J_{S}
$$

where D is the solute diffusion coefficient and C is the solute concentration. Integrating Equation 12 over the effective length of the porous support for the feed solution and the $\delta$ boundary layer for the draw solution and assuming uniform bulk concentrations exist within the channels outside of the porous support and boundary layer results in an effective osmotic pressure difference given by [6]:

$$
\Delta \pi_{e f f}=\frac{\pi_{D, b} \exp \left(-\frac{J_{w}}{k}\right)-\pi_{F, b} \exp \left(J_{w} K\right)}{1+\frac{B}{J_{w}}\left[\exp \left(J_{w} K\right)-\exp \left(-\frac{J_{w}}{k}\right)\right]}
$$

where $\mathrm{k}$ and $\mathrm{K}$ are the mass transfer coefficient for the draw solution and the solute resistivity of the porous support, respectively. Substituting Equation 13 into Equation 10 and Equation 11, the water and salt fluxes, accounting for ECP and ICP, are given by:

$$
J_{W}=A\left\{\frac{\pi_{D, b} \exp \left(\frac{-J_{W}}{k}\right)-\pi_{F, b} \exp \left(J_{W} K\right)}{1+\frac{B}{J_{W}}\left[\exp \left(J_{W} K\right)-\exp \left(\frac{-J_{W}}{k}\right)\right]}-\Delta P\right\}
$$




$$
J_{S}=B\left\{\frac{C_{D, b} \exp \left(\frac{-J_{W}}{k}\right)-C_{F, b} \exp \left(J_{W} K\right)}{1+\frac{B}{J_{W}}\left[\exp \left(J_{W} K\right)-\exp \left(\frac{-J_{W}}{k}\right)\right]}\right\}
$$

Equation 15

At each membrane segment, the set of nonlinear equations (Equation 14 and Equation 15) are solved using the Newton-Raphson method. The concentrations, pressures, and velocities of each differential volume are assumed to be uniform. The derivation of Equation 14 and Equation 15 relies on the assumption of bulk flow conditions to describe the concentration polarization effects. This assumption ignores variations in flow velocity and dead zones (Figure 2a) that would be found in a working PRO module. This assumption may ultimately cause a slight over-estimation of the water flux through the membrane.

\subsubsection{Module and membrane characteristics}

The volume of space inside a standard 8-inch by 40 -inch module was used as the basis for determining the heights of the feed and draw channels. The membrane thickness is assumed to be $120 \mu \mathrm{m}$, and the central feed/collection tube is assumed to have a $3.81 \mathrm{~cm}$ diameter. The relative heights of the feed and draw channels are determined by the optimization model as they are highly dependent on the relative feed and draw flow rates. The porosity of the spacer reduces effective cross-sectional area of each channel, and it is assumed to be 0.72 (Table 1). The direct interference of the spacers with water flux through the membrane via the 'shadow effect' [23] is also not included in this model; this may cause an overestimation of water flux and power produced. The membrane characteristics (A, B, and S) used in this model (Table 1) are representative of a thin film composite (TFC) membrane previously used experimentally [17]. 
Table 1

\subsubsection{Module power calculations}

While the theoretical work extracted from the PRO process is given by Equation 1, in practice, PRO is a fixed pressure process [7], with the system work described by the following thermodynamic relation:

$$
\text { Work }=\Delta P \Delta V
$$

Equation 16

Where $\Delta \mathrm{P}$ is the applied hydraulic pressure and $\Delta \mathrm{V}$ is the water flux across the membrane (the permeate volume). Equation 16 takes into account that due to a fixed $\Delta \mathrm{P}$, the water permeation will end when $\Delta \pi_{\text {eff }}$ $=\Delta \mathrm{P}$, thus leaving an amount of potential energy unutilized. The power density of the membrane and the specific energy of the PRO process are evaluated at the end of the module. Using Equation 16 as the basis of calculating the power density of the membrane, the power density of the membrane is given by:

$$
W=\frac{Q_{p, t o t a l} \Delta P_{n e t}}{A_{\text {total }}}
$$

Equation 17

where $W$ is the membrane power density, $Q_{p, t o t a l}$ is the total permeate flow rate across the entire membrane, which is calculated by summing the permeate flow from each step in the model, $\Delta P_{\text {net }}$ is the net hydraulic pressure difference across the entire membrane, and $A_{\text {total }}$ is the total area of the membrane. Specific energy was also calculated at the end of the model, which is given by the work done by PRO normalized to the permeate flow. Thus, the specific energy is effectively given by:

$$
S E=\Delta P_{n e t}
$$




\subsubsection{Membrane module configurations}

\subsection{Configuration 1: modules in parallel}

The first subsystem configuration places single membrane modules in parallel pressure vessels holding one membrane each (Figure 5). Each pressure vessel would be stacked in a rack system very similar to a reverse osmosis desalination facility. Vertical feed and draw lines would supply water at the head end of the modules. This allows for feed and recovery lines to run laterally along each membrane rack unit. Each rack, or bank, of modules would include a shutoff valve for maintenance or backwashing.

\section{Figure 5}

\subsection{Configuration 2: Tiered with seawater Refill}

The second subsystem configuration places parallel pressure vessels where the fresh water effluent from a first tier is recycled into the next tier (Figure 6). This configuration attempts to maximize utilization of the treated freshwater resource. Undiluted seawater is introduced to each tier of pressure vessels. Each successive tier has a number of vessels dependent on the percent permeate of the previous tier, and tiers continue until the total freshwater usage is greater than or equal to $90 \%$.

The benefit of this configuration is in maximizing the utilization of the freshwater resource. Freshwater pretreatment is the most energy intensive process in the proposed facility, and any freshwater that does not cross the membrane to produce power is essentially wasted. This configuration maximizes the ratio of permeate to feed flow rate, reducing the amount of specific energy required to treat freshwater.

Figure 6

\subsubsection{Freshwater conveyance and pretreatment}

The freshwater pretreatment system includes piping, appurtenances, and Memcor CMF membrane microfiltration (MF) (Evoqua, Warrendale, PA) treatment. Feed water quality requirements for PRO are 
assumed to be comparable to that for RO: treatment alternatives must remove suspended and dissolved solids resulting in a feed water turbidity of less than $0.5 \mathrm{NTU}$ [24]. The pilot facility operated by Statkraft employed MF filtration pretreatment which achieved higher feed quality than 0.5 NTU [21]. The average, median, and mode upper range effluent turbidities of the Memcor microfiltration system case studies are 0.16 NTU, 0.065 NTU, and 0.06 NTU, respectively [25]. Effluent turbidity is dependent on influent water quality and constituents. Energy costs associated with MF treatment include feed/permeate pumps, backwash pumps, blowers, process air compressors, heating of cleaning solutions, and a booster pump to raise the pressure from approximately 10 psi to 30 psi for the PRO membranes [25]. The design also accounts for providing the pressure necessary to move water through the facility to the PRO modules and then to the outfall wet well. Evaluation of head loss and pumping requirements was conducted with the aid of EPANET, a free software package used to model water distribution systems made available by the EPA [26]. The calculated specific energy of the freshwater pumping and pretreatment normalized to the feed flowrate are $0.0226 \mathrm{kWh} / \mathrm{m}^{3}$ and $0.0439 \mathrm{kWh} / \mathrm{m}^{3}$, respectively (Table 2).

\subsubsection{Seawater conveyance \& pretreatment}

The seawater pretreatment system is designed to provide draw solution to the PRO system at a quality level that minimizes fouling and energy usage. Seawater pretreatment is assumed to be comparable to that required for RO desalination. As membrane-based treatment systems are found to have lower environmental impacts and greater energy savings than conventional treatment systems [24], the proposed treatment is a membrane-based submerged UF system, which is often preceded by a 50-500 micron strainer [27]. Numerous proprietary UF membrane systems are commercially available. ZeeWeed® 1000

(GE Water, Trevose, PA) and Memcor ${ }^{\circledR}$ CS (Evoqua, Warrendale, PA) are both submerged systems which require less energy than encased systems due to higher operating pressures required for encased membrane treatment [25]. 
The preferred conveyance system consists of constructing a deep-water intake with wedge-wire direct intake structures. The deep-water intake is the preferred alternative because it provides better water quality and reduced marine impacts (as compared to shallow and surface water intake systems) [28]. Wedge-wire screens are preferred because they most effectively reduce impingement and entrainment [29] while adding very little friction head loss [30]. The energy requirements in Table 2 are calculated using ZeeWeed ${ }^{\circ} 1000$ product data combined with the pumping requirements of a new deep-water intake with wedge-wire intake structures. The specific energy is normalized to the seawater flow rate here and later normalized to the permeate flow rate for calculating $\mathrm{SE}_{\text {net }}$.

Table 2

\subsubsection{Turbine and generator}

Although PRO is an emerging technology, the application of a hydro-turbine and generator within the PRO system is essentially the same as in classical hydropower systems. Instead of using a reservoir with a penstock or an in-stream/run-of-river turbine, a portion of the pressurized draw solution flow is diverted through the turbine. Turgo, Cross-flow, Pelton, and Francis turbines were evaluated based on efficiency and effluent pressure. Turbine efficiencies are $90.1 \%$ for Pelton [31], 84.9\% for Turgo [31], 84\% for Cross-flow [32] and $>90 \%$ for Francis [33]. A Francis turbine design is selected as the preferred alternative because the efficiency is high and the pressure on the discharge can be tuned to provide enough energy to move the brackish solution to the outfall wet well $\left(0.011 \mathrm{kWh} / \mathrm{m}^{3}\right.$ of dilute seawater). The overall efficiency of a Francis turbine system is calculated to be $87 \%$ based on the pressure and range of flow rates provided by preliminary results of the model. A three-phase induction generator provides power with simple operation and lower maintenance cost. Generator efficiency is assumed to be 95\% [3436]. 


\subsubsection{ERDs and pumps}

Pressure exchangers, the type of ERDs employed in PRO applications, reduce the energy requirement of pressurizing the draw solution by transferring the pressure from the brackish discharge to the incoming draw solution. The discharge flow matches the draw solution because the diversion of pressurized brackish solution is equivalent to the flow rate of water permeating through the membranes. Two styles of isobaric energy recovery devices were evaluated for use in a PRO facility: DWEER (Flowserve, Irving, TX), and the PX-Q300 (Energy Recovery Inc., San Leandro, CA). Both models have operating efficiencies between 96\% and 98\%. Higher efficiencies correspond with lower flow rates through the Pressure exchangers, so there exists a tradeoff between capital cost and energy efficiency. The PX-Q300 was selected and a conservative assumption of 96\% efficiency was used for the pressure exchangers in the facility. Circulation pumps are necessary to overcome pipe friction and deliver the brackish water from the pressure exchanger to the wet well of the outfall. Efficiencies for low head, high-flow pumps are expected to be $83 \%$.

\subsection{Facility-Scale Optimization}

The facility-scale optimization combines the PRO simulation model with the facility subsystem energy requirements, resulting in the net specific energy of the facility. The optimization is responsible for finding the flow rates, input pressures, feed and draw channel heights, and total membrane area that maximize the net power within the fixed facility design capacity of 30 MGD.

\subsubsection{Linked Simulation-Optimization}

The linked simulation-optimization (LSO) model formulated for this investigation linked a PRO simulation model with a gradient-based optimization package to determine the optimal design and operation parameters of a PRO module and PRO facility, respectively. The PRO simulation model 
developed is based on the theoretical assumptions described in Section 2.1.1. The optimization package used in the study was Modular In-core Nonlinear Optimization System (MINOS), which is a software package for solving large-scale optimization problems developed by the Stanford Optimization Laboratory [37]. The overall process flow is described in Figure 7. MINOS feeds the input parameters to the simulation model, which calculates the gross power produced and the energy requirements of freshwater and seawater pretreatment. The net power is then calculated as the difference between these two values. The input parameters are then varied by MINOS and this process is repeated until a maximum net power is reached. MINOS was used in conjunction with the simulation model to determine the optimal system flowrates, applied hydraulic pressures, channel heights, and membrane area to maximize the net power. This methodology is referred as a linked simulation-optimization (LSO) approach.

Figure 7

\subsubsection{Optimization Model}

The objective function of the optimization model that is used to maximize the total plant power is written as:

$$
\max z=\text { power gain }- \text { power cost } \quad \text { Equation } 19
$$

where the power gain is the positive power output from the turbine, and the power cost is the cost of treating and pumping both the salt and fresh water to the limits required by the PRO membrane modules. The optimization model is subject to the following constraints:

$$
P_{\min } \leq P \leq P_{\max } \quad \text { Equation } 20
$$

where P represents the array of parameters set in MINOS. The optimization model is heavily affected by appropriate bounds set in MINOS. The bounds on the parameters are determined via a general understanding of the physics of the problem and a series of trial and error runs. 
FO membranes are used in most module-scale lab tests of PRO [8, 13, 17], but FO module parameters are not optimized for PRO. Therefore, membrane module parameters are used as decision variables in MINOS for maximizing the net power of the PRO facility. Too many decision variables causes MINOS to have very long computational times and often results in a failure to find an optimum. Therefore, the number of leaves, baffles, and membrane area per module were optimized separately from the LSO, while the channel heights and total number of modules are included as decision variables.

\subsubsection{Parameter determination}

\subsubsection{Leaves per module}

The number of leaves per module affects the geometry of the feed flow path only. The total membrane area is fixed for each model run. Each additional leaf adds a parallel flow path for the feed water, causing the effective channel to widen, and the overall flow path to shorten. Figure 8 shows the percent increase in net power as a function of increasing the number of membrane leaves within an 8-inch membrane module. Percent change in net power is calculated by dividing the net power achieved with different leaves per module by the net power achieved with one leaf per module. As the number of leaves increases, the percent change in net power increases as friction losses in the feed channel drop as a result of reduced feed velocities and travel distances. However, the percent increase in net power diminishes as the number of leaves increases. The model assumes 20 leaves per module; this reduces the number of decision variables sent to MINOS without significantly reducing the optimal net power.

Figure 8

\subsubsection{Baffles}

The number of baffles per membrane leaf affects the width of the feed channel and flow path length of the feed channel. As the number of baffles increases, the flow path lengthens and the effective channel width decreases for a fixed membrane area. As the number of leaves increases, the flow path shortens and the 
effective channel width increases. To avoid sending redundant decision variables to MINOS, the number of baffles is fixed at one per leaf, and the number of leaves was optimized as shown in Figure 8.

\subsubsection{Area per module}

The membrane area per module determines the cross sectional area available for the feed and draw channels. The channel height ratio determines the ratio of the feed channel height to the draw channel height. Both of these decision variables change the cross sectional area of the feed and draw channels, thereby influencing the pressure losses through the module. These two decision variables cause MINOS to fail to find optimal parameters during preliminary runs of the LSO (results not shown).

The membrane area per module and the total number of membrane modules determine the amount of membrane area available for the design flow. As the membrane area increases, friction losses and percent permeate also increase. These two decision variables change the amount of area available at different rates, also causing MINOS to fail (results not shown). Since the area per module has these competing effects with the channel height ratio and the total number of modules, the membrane area that achieves the highest net power is determined via a sensitivity investigation separately from the LSO. The membrane area per module is determined by running the LSO multiple times for tiered and parallel flow configurations. For both configurations the maximum net power occurs at $53 \mathrm{~m}^{2} /$ module (Figure 9). Membrane area per module is included as a material parameter and not a decision variable in the final LSO (Table 3).

Figure 9

\subsubsection{Model Inputs}

The module and configuration parameters (Table 3) are kept constant in the LSO model, and the decision variables (Table 4) are varied by MINOS to reach a maximum net power. Final results and optimization are conducted with a 3:1 tiered system (Figure 6), as the 2-tier configuration achieved higher permeate 
flow and net specific energy than the simple parallel configuration via preliminary LSO runs (data not shown).

Table 3

Table 4

\subsection{Power Density and Net Specific Energy Sensitivity Analysis}

The sensitivity of power density and net specific energy of the facility is investigated in relation to the membrane area, number of membrane leaves, system flow rates, system pressures, and solution concentrations. The goal is to discover the most sensitive operating parameters by comparing the trends in power density with the trends in net specific energy. Sensitivity analysis was conducted by selecting starting point system flow rates, pressures, and membrane area that result in a power density of approximately $5 \mathrm{~W} / \mathrm{m}^{2}$. The range of parameter perturbation is selected to include a peak in net specific energy. This approach to sensitivity analysis recognizes the importance of the $5 \mathrm{~W} / \mathrm{m}^{2}$ power density benchmark while simultaneously showing the behavior of the net specific energy. Sensitivity analysis is conducted on power density and net specific energy as membrane area per module varies from 32 to 56 $\mathrm{m}^{2}$, draw flow rate varies from 64 to $120 \mathrm{~m}^{3} /$ day, feed flow rate varies from 48 to $90 \mathrm{~m}^{3} /$ day, draw pressure varies from 167 to 273 psi, and feed pressure varies from 3.6 to 11 psi.

\section{Results and Discussion}

\subsection{Simulation Validation}

To validate the model simulation of the PRO modules, results were compared to experimental data of a PRO membrane module performed by Kim and coworkers [16]. A prototype 8040 PRO module was used in their study, and the authors experimentally determined the relationship between applied hydraulic pressure and water permeability coefficient (A) and salt permeability coefficient (B). The structural parameter (S) was calculated from the A and B values experimentally determined at hydraulic pressure 
differences of 7.8, 11.7 and 15.7 bar [16]. The average S value from these 3 pressure differences was used in the model validation. S was calculated with the following relationship [38]:

$$
S=\frac{D}{J_{w}} \ln \left(\frac{B+A \pi_{d}}{B+J_{w}}\right)
$$

Equation 21

Where $\mathrm{D}$ is the diffusion coefficient of the draw solute and $\pi_{\mathrm{d}}$ is the osmotic pressure of the bulk draw solution. The value of D used for this validation is $1.533 \mathrm{e}-9 \mathrm{~m}^{2} / \mathrm{s}$ : the diffusion coefficient of seawater at $25^{\circ} \mathrm{C}[39]$.

Water flux and power density were simulated at various $\Delta \mathrm{P}$ values (Figure 10) and compared to the experimental results in the Kim and coworkers study [16]. The model input parameters (A, B, S, concentrations, channel heights, flow rates and pressures) match the experimental input values. For all simulations, a draw concentration of $35 \mathrm{~g} / \mathrm{L}$ and feed concentration of $0.5 \mathrm{~g} / \mathrm{L}$ was used. The feed and draw flow rates were held constant at 7 LPM and 22.5 LPM, respectively.

Figure 10

The water flux decreases as $\Delta \mathrm{P}$ increases at the same rate for both the model simulations and experimental results (Figure 10a). The simulation most likely overestimates water flux because the model does not account for membrane deformation [40, 41], spacer shadow effect [16], and dead zones within the module envelopes, all of which work to effectively reduce the water flux observed in experimental studies. Power density increases to a maximum and then decreases for both the model and experimental results (Figure 10b). However, the maximum power density occurs at a higher pressure and the power density decreases more slowly at higher pressures for the model (Figure 10b). The discrepancy between the model power density and the observed power density at higher $\Delta \mathrm{P}$ values (Figure 10b) is most likely due to reduced water flux and the increased effect of $\Delta \mathrm{P}$ on power density at higher pressures (Equation 17). Water flux through the membrane could also be diminished by reverse salt flux which is higher in physical tests than in model predictions [42]. Additionally, Kim and coworkers [16] found that the salt 
permeability coefficient, $\mathrm{B}$, increased with increasing pressure, leading to a lower $\Delta \pi_{\mathrm{eff}}$, and thus lower water flux at elevated pressure.

\subsection{Facility-scale optimization}

The optimal flow rates, applied pressures, total number of modules, feed to draw channel ratio, and the percent permeate were determined for the parallel configuration and the tiered alternative using the LSO model (Table 5). The feed flow ratio and total number of modules are greater in the parallel configuration than in the tiered configuration, while the draw pressure and percent permeate are higher in the tiered configuration. The draw pressures are higher for the tiered configuration partly due to the higher feed pressure that is necessary to sustain the feed water flow through the second tier of modules. The ratio of feed/draw channel heights is also greater for the parallel configuration due to the greater feed flow rate. The differences between the two module configurations are the result of MINOS attempting to maximize percent permeate and draw pressure while minimizing friction losses and draw flow rate.

Table 5.

Power density, facility net power, permeate specific energy, and net specific energy are reported in Table 6. The power density is greater for the tiered configuration because the total number of modules (which represents total membrane area) is lower and the power output is higher (Table 5 and Table 6). The net power obtained from treating and conveying 30 MGD of combined fresh water and seawater is $120 \mathrm{~kW}$ and $152 \mathrm{~kW}$ for the parallel and tiered configurations, respectively. The specific energy of the membrane module is $0.38 \mathrm{kWh} / \mathrm{m}^{3}$ and $0.42 \mathrm{kWh} / \mathrm{m}^{3}$ for parallel and tiered configurations, respectively. The net specific energy for the tiered configuration is higher because the draw pressure and percent permeate are higher. Overall, this suggests that a tiered configuration may be the preferred method to arrange membrane modules to maximize resource utilization. 
Table 6.

The optimal volumetric fraction of the feed solution to the total influent is $\sim 40 \%$ in a $3: 1$ tiered configuration. At this fraction, the Gibbs free energy of mixing (Equation 1) is $0.56 \mathrm{kWh} / \mathrm{m}^{3}$ (Figure 11). At the theoretical optimum fixed pressure, the maximum extractable work through PRO is $0.44 \mathrm{kWh} / \mathrm{m}^{3}$ (Equation 2, Figure 11). The net specific energy produced by the system is approximately $0.12 \mathrm{kWh} / \mathrm{m}^{3}$ : $17 \%$ of the free energy of a river meeting the ocean.

Figure 11

The turbine and generator, freshwater treatment, seawater treatment, and module subsystems require significant infrastructure, operations and maintenance, and energy consumption compared to the low net power and net specific energy output of the facility (Table 6). Figure 12, a Sankey diagram, is a visual representation of the energy lost in the facility-scale PRO system. The parasitic loads are approximately equivalent to the theoretical losses, leaving only $17 \%$ of the energy remaining for positive gain. The energy losses are small for non-ideal osmosis and feed channel friction losses because of the optimization and the assumptions made about spacers, module geometries and membrane characteristics. The estimate for net specific energy displayed in Figure 12 may be optimistic as module scale tests showed that PRO modules have greater energy losses than the ones captured by the module simulation due to channel deformation, spacer turbulence, module geometry and non-linear behavior of A, B and the structural parameter $[16,17]$.

Figure 12.

In a case study by Maisonneuve and coworkers [43], the parameters of a commercially available PRO membrane were used in a simulation model that takes into account the detrimental effects of concentration polarization and friction within the module, as well as parasitic loads such as pressure losses due to pre-treatment filtration and losses due to inefficiencies in the pumps, motors, pressure 
exchanger, turbine, and generator [13]. This investigation used parameters that were representative of installing the PRO system in Quebec, Canada. Using optimal applied hydraulic pressure and flow rates, Maisonneuve and coworkers found that the maximum net power achievable is $0.85 \mathrm{~W} / \mathrm{m}^{2}$, which is $2.4 \%$ greater than the net power density calculated in the current investigation $\left(0.83 \mathrm{~W} / \mathrm{m}^{2}\right)$. A comparison to other module and facility-scale studies in the literature is shown in Table 7.

Table 7

Although operational parameters vary greatly between studies, making comparisons between power densities, specific energy and optimal feed to draw ratios difficult, this comparison shows that the achievable net power density with river-to-sea PRO is approximately $1 \mathrm{~W} / \mathrm{m}^{2}$. The optimal feed to draw ratio appears to have no consistency between studies; it is likely to depend heavily on assumptions made within each study. The large variation across studies also highlights the sensitivity of the PRO process to differences in operational and membrane module parameters.

\subsection{Sensitivity Analysis}

\subsubsection{Membrane Area}

Figure 13 shows power density and net specific energy as function of membrane area. As membrane increases, power density decreases while net specific energy increases to a maximum before decreasing. Power density decreases as membrane area increases because power density is inversely proportional to membrane area (Equation 17). Net specific energy first increases as membrane area increases because the percent permeate increases, then reaches a maximum and decreases because friction losses in the feed and draw channels dominate. Friction losses in the feed and draw channels increase because the increasing membrane area causes the channels to shrink (Section 2.1.1.3). Net specific energy is lower than the optimum because flow rates and input pressures are selected to achieve $\sim 5 \mathrm{~W} / \mathrm{m}^{2}$ power density. 
Figure 13.

\subsubsection{Flow Rates}

Figure 14 shows power density and net specific energy versus draw and feed flow rate, respectively. In Figure 14a, the power density increases as draw flow rate increases while net specific energy increases to a maximum then decreases with increasing draw flow rate. The power density increases with increasing draw flow rate because the dilution fraction (Equation 1) decreases. The net specific energy increases because the permeate increases, finds a maximum, and decreases because the energy requirements of pumping and treating the draw solution outweigh the benefits of increased permeate. In Figure 14b, both power density and net specific energy increase to a maximum and then decrease as feed flow rate increases. Power density and net specific energy increase because permeate increases and decrease because the permeate rate decreases after reaching a maximum. Net specific energy decreases more rapidly with increasing feed flow rate because percent permeate decreases and friction losses increase with increasing feed flow rate. Specific energy values are negative for Figure 14 because the feed and draw pressures and flow rates were selected to achieve $\sim 5 \mathrm{~W} / \mathrm{m}^{2}$ power density and to do so the energy costs of pumping outweigh the energy production.

Figure 14

\subsubsection{Pressures}

Figure 14 shows power density and net specific energy versus draw and feed pressure. In Figure 14a, the power density and net specific energy increase to a maximum and then decrease as draw pressure increases. The power density and net specific energy increase because draw pressure determines $\Delta \mathrm{P}$, Work, and W (Equation 16 and Equation 17). Power density and net specific energy reach a maximum and decrease because permeate decreases after increasing to a maximum. The draw pressure that maximizes both the power density and net specific energy is approximately 205 psi, the same as in the parallel module configuration (Table 5). In Figure 14b, power density increases with increasing feed 
pressure while net specific energy decreases with increasing feed pressure. Power density increases with increasing feed pressure because the permeate increases. Net specific energy decreases as feed pressure increases because the energy cost of increasing the feed pressure is greater than the energy gain of the increased permeate.

Figures 15

\section{Conclusions}

In this investigation, the net specific energy consumption of a river-to-sea PRO facility was evaluated using a novel simulation and optimization method that integrates parasitic loads and efficiencies of the PRO facility components. Although this PRO configuration represents a source of renewable energy, the overall specific energy that may be recovered is quite low at approximately $0.1 \mathrm{kWh}$ per $\mathrm{m}^{3}$ of fresh water when all the parasitic loads are accounted for. Freshwater and seawater pretreatment and conveyance were found to be the main parasitic loads. These loads could perhaps be reduced with technological breakthroughs in membrane materials and antifouling properties $[44,45])$ that would allow for lower energy requirements for pretreatment. Even with a “perfect” membrane, the maximum specific energy recovered could be approximately $0.4 \mathrm{kWh}$ per $\mathrm{m}^{3}$ of fresh water. To put this in perspective, a household in the United States generates approximately $1 \mathrm{~m}^{3}$ of wastewater per day, and at the same time consumes approximately $30 \mathrm{kWh}$ [46]. By contrast a photovoltaic panel of $0.40 \mathrm{~m}^{2}$ would generate $0.4 \mathrm{kWh}$ in a day [47].

On the other hand, PRO could have niche applications when high salinity brines can be utilized, as the specific energy linearly increases as the osmotic pressure difference between the solution increases (i.e., double specific energy with double osmotic pressure difference). For example, PRO may help reduce seawater desalination energy consumption in the so-called reverse osmosis (RO)-PRO system [8, 48]. This system, in addition to the elevated draw solution salinity would also have reduced parasitic loads compared to the river-to-sea configuration as the draw solution is already pre-treated before RO and the 
turbine-generator is not employed. PRO may also have application in a closed-loop configuration to convert waste heat into useful work [49]. In this configuration, elevated draw solution salinity would be beneficial to convert energy from the waste heat at higher rates, making the system more compact and more efficient.

\section{Acknowledgements}

The authors thank the Humboldt State University Environmental Resources Engineering students from the Fall 2013 Senior Capstone Design course, T.K. Williams, the Humboldt Bay Municipal Water District (HBMWD), and the Humboldt Bay Harbor, Recreation \& Conservation District for their help in the facility analysis. Lori Jones was partially funded by the USDA National Food and Agriculture Grant no. 2011-38422-31204.

\section{References}

[1] S. Fuss, Szolgayova, J., Khabarov, N., Obersteiner, M., Renewable and climate change mitigation: Irreversible energy investment under uncertainty and portfolio effects, Energy Policy, 40 (2012) 59-68.

[2] R. Norman, Water Salination: A Source of Energy, Science, 186 (1974) 350-352.

[3] T. Thorsen, Holt, T., The potential for power production from salinity gradients by pressure retarded osmosis, Journal of Membrane Science, 335 (2009) 103-110.

[4] Ren21, Renewables 2015 Global Status Report, 2015.

[5] S. Loeb, Mehta, G., A two-coefficient water transport equation for pressure-retarded osmosis, J. Membr. Sci., 4 (1979) 351-362.

[6] K. Lee, Baker, R., Lonsdale, H., Membranes for power generation by pressure-retarded osmosis, J. Membr. Sci., 8 (1981) 141-171.

[7] N. Yip, Elimelech, M., Thermodynamic and Energy Efficiency Analysis of Power Generation from Natrual Salinity Gradients by Pressure Retarded Osmosis, Environmental Science \& Technology, 46 (2012) 5230-5239.

[8] J.L. Prante, J.A. Ruskowitz, A.E. Childress, A. Achilli, RO-PRO desalination: an integrated lowenergy approach to seawater desalination, Appl. Energy, 120 (2014) 104-114. 
[9] N. Yip, Elimelech, M., Comparison of Energy Efficiency and Power Density in Pressure Retarded Osmosis and Reverse Electrodialysis, Environmental Science \& Technology, 48 (2014) 11002-11012.

[10] J. Johnson, Busch, M., Engineering Aspects of Reverse Osmosis Module Design, in, Lenntech, 2009.

[11] S. Skilhagen, Dugstad, J., Aaberg, R., Osmotic power - power production based on the osmotic pressure difference between waters with varying salt gradients, Desalination, 220 (2008) 476-482.

[12] A.P. Straub, N.Y. Yip, M. Elimelech, Raising the Bar: Increased Hydraulic Pressure Allows Unprecedented High Power Densities in Pressure-Retarded Osmosis, Environmental Science \& Technology Letters, 1 (2014) 55-59.

[13] J. Maisonneuve, Pillay, P., Laflamme, C., Pressure-retarded osmotic power system model considering non-ideal effects, Renewable Energy, 75 (2015) 416-424.

[14] J. Post, Veerman, J., Hamelers, H., Euverink, G., Metz, S., Nymeijer, K., Buisman, C., Salinitygradient power: Evaluation of pressure-retarded osmosis and reverse electrodialysis, Journal of Membrane Science, 288 (2007) 218-230.

[15] A. Straub, Lin, S., Elimelech, M., Module-Scale Analysis of Pressure Retarded Osmosis: Performance Limitations and Implications for Full-Scale Operation, Environmental Science \& Technology, 48 (2014) 12435-12444.

[16] Y.C. Kim, Kim Y., Oh, D., Lee, K., Experimental Investigation of a Spiral-Wound PressureRetarded Osmosis Membrane Module for Osmotic Power Generation, Environmental Science \& Technology, 47 (2013) 2966-2973.

[17] A. Achilli, Prante, J., Hancock, N., Maxwell, E., Childress, A., Experimental Results from RO-PRO: A Next Generation System for Low-Energy Desalination, Environmental Science \& Technology, 48 (2014) 6437-6443.

[18] J. Post, Hamelers, H., Buisman, C., Energy Recovery from Controlled Mixing Salt and Fresh Water with a Reverse Electrodialysis System, Environmental Science \& Technology, 42 (2008) 5785-5790.

[19] N. Yip, Elimelech, M., Performance Limiting Effects in Power Generation from Salinity Gradients by Pressure Retarded Osmosis, Environmental Science \& Technology, 45 (2011) 10273-10282.

[20] A. Achilli, T.Y. Cath, A.E. Childress, Power generation with pressure retarded osmosis: an experimental and theoretical investigation, J. Membr. Sci., 343 (2009) 42-52.

[21] Statkraft, Statkraft: Energy Sources, in: Technology, 2013.

[22] E. Bar-Zeev, F. Perreault, A.P. Straub, M. Elimelech, Impaired Performance of Pressure-Retarded Osmosis due to Irreversible Biofouling, Environmental Science \& Technology, (2015). 
[23] Y. Kim, Elimelech, M., Adverse Impact of Feed Channel Spacers on the Performance of Pressure Retarded Osmosis, Environmental Science \& Technology, 46 (2012) 4673-4681.

[24] T. Al-Sarkal, Hassan, A., Ultrafiltration versus sedimentation-based pretreatment in Fujairah-1 RO plant: Environmental impact study, Desalination, 317 (2013) 55-66.

[25] AWWA, Manual of Water Supply Practices: Book 53, 2005.

[26] US EPA, EPANET, 2015.

[27] V. Bonnelye, Guey, L., Castillo, J., UF/MF as RO pre-treatment: the real benefit, Desal., 222 (2008) 59-65.

[28] E.P.R. Institute, Case study 2: Evaluation of wedgewire screen for protecting early life stages of fish as CWIS, Power, (2005) 48-49.

[29] T. Pankratz, Seawater Intake and Outfall Cost Aspects, in, CH2M Hill, 2009.

[30] US EPA, Economic and Engineering Analyses of the Proposed 316(b) New Facility Rule, in, Washington, D.C., 2000.

[31] C.C. Warnick, Hydropower Engineering, Englewood Cliffs: Prentice-Hall, 1984.

[32] N. Aziz, Desai, V., An Experimental Study of the Effect of Some Design Parameters in Cross-Flow Turbine Efficiency, Engineering Report, Department of Civil Engineering, Clemson University, (1991).

[33] C. Hydro, Hydro Systems for Utilities and IPPs, in, 2013.

[34] R. Schultz, Introduction to Electric Power Engineering, Harper \& Row, New York, 1985.

[35] J. Raabe, Hydro Power: The design, use, and function of hydromechanical, hydraulic and electrical equipment, VDI Verlag, 1985.

[36] S. Heng, Design of a 5 kW microhydro generating set, Electrical Equipment, (1992).

[37] B.A. Murtagh, M.A. Saunders, MINOS 5.5 User's Guide, in, Stanford University Systems Optimization Laboratory, 2013.

[38] N. Yip, Tiraferri, A., Phillip, W., Schiffman, J., Hoover, L., Kim, Y., Elimelech, M., Thin-Film Composite Pressure Retarded Osmosis Membranes for Sustainable Power Generation from Salinity Gradients, Environmental Science \& Technology, 45 (2011) 4360-4369.

[39] M.H. Sharqawy, J.H. Lienhard, S.M. Zubair, Thermophysical properties of seawater: a review of existing correlations and data, Desal. Water Treat., 16 (2012) 354-380. 
[40] Y. Li, R. Wang, S. Qi, C. Tang, Structural stability and mass transfer properties of pressure retarded osmosis (PRO) membrane under high operating pressures, Journal of Membrane Science, (2015) 143153.

[41] G. Han, S. Zhang, X. Li, T. Chung, Progress in pressure retarded osmosis (PRO) membranes for osmotic power generation, Progress in Polymer Science, (2015) 1-27.

[42] A. Straub, C. Osuji, T. Cath, M. Elimelech, Selectivity and Mass Transfer Limitations in PressureRetarded Osmosis at High Concentrations and Increased Operating Pressures, Environmental Science \& Technology, (2015) 12551-12559.

[43] J. Maisonneuve, P. Pillay, Osmotic Power Prototype for Generating Electricity and Reducing Greenhouse Gas Emissions in Remote Regions of Quebec, EIC Climate Change Technology Conference 2015, (2015).

[44] Y.-x. Shen, W. Si, M. Erbakan, K. Decker, R. De Zorzi, P.O. Saboe, Y.J. Kang, S. Majd, P.J. Butler, T. Walz, A. Aksimentiev, J.-l. Hou, M. Kumar, Highly permeable artificial water channels that can selfassemble into two-dimensional arrays, Proceedings of the National Academy of Sciences, 112 (2015) 9810-9815.

[45] Q. Yang, B. Mi, Nanomaterials for Membrane Fouling Control: Accomplishments and Challenges, Advances in Chronic Kidney Disease, 20 (2013) 536-555.

[46] US DOE, How much electricity does an American home use?, U.S. Energy Information Administration, Washington, DC, 2014.

[47] Grape Solar, 390 W Mono-crystalline PV Modules, in: Small Off-Grid, 2014.

[48] M. Kurihara, M. Hanakawa, Mega-ton Water System: Japanese national research and development project on seawater desalination and wastewater reclamation, Desal., 308 (2013) 131-137.

[49] A.E. Childress, A. Achilli, E.M.V. Hoek, V.V. Tarabara, Pressure-Retarded Osmosis, in: Encyclop. Mem. Sci. Technol., John Wiley \& Sons, Inc., 2013. 
Table 1. List of material parameters used in the simulation model. These values are incorporated into a standard 8040 module. Values for A, B, and S are taken from [17].

\begin{tabular}{|cc|}
\hline Parameter & Value \\
\hline Water Permeability Coefficient [m/day kPa] & 0.00123 \\
Salt Permeability Coefficient [m/day] & 0.00208 \\
Structural Parameter [m] & 0.000310 \\
Length of Membrane Module [m] & 1.016 \\
Thickness of Membrane [m] & 0.00012 \\
Diameter of Pressure Vessel [m] & 0.2032 \\
Diameter of Feed Pipe in Module [m] & 0.03810 \\
Spacer Porosity of Draw Channel [-] & 0.72 \\
Spacer Porosity of Feed Channel [-] & 0.72 \\
\hline
\end{tabular}

Table 2. Specific energy requirements of the seawater and freshwater intake and pretreatment. Energy is normalized to their respective treated volumes.

\begin{tabular}{|c|lcc|}
\hline & Component & $\begin{array}{c}\text { Specific energy } \\
\text { required }\left(\mathrm{kWh} / \mathrm{m}^{3}\right)\end{array}$ & $\begin{array}{c}\text { Total } \\
\left(\mathrm{kWh} / \mathrm{m}^{3}\right)\end{array}$ \\
\hline Seawater & & 0.0853 \\
& Intake conveyance & 0.0075 & \\
& UF operation & 0.0664 & \\
& Circulation pumps & 0.0114 & \\
\hline Freshwater & & & 0.0665 \\
& Water circulation & 0.0226 & \\
& MF operation & 0.0439 & \\
\hline
\end{tabular}

Table 3. List of membrane module characteristics and arrangement. Membrane area represents the aggregate area of all the membrane leaves in the module. The membrane area and the number of leaves per module are derived from the sensitivity analysis and optimization.

\begin{tabular}{|cc|}
\hline Description & Value \\
\hline Total area of membrane $\left[\mathrm{m}^{2}\right]$ & 53 \\
Number of leaves per module & 20 \\
Number of baffles per leaf & 1 \\
$\begin{array}{c}\text { Number of modules feeding each } \\
\text { module in the } 2^{\text {nd }} \text { tier }\end{array}$ & 3 \\
\hline
\end{tabular}


Table 4. List of the decision variables in MINOS and the model output they directly influence.

\begin{tabular}{|cc|}
\hline Decision variables & Primary influences \\
\hline Entering draw pressure & power output, permeate \% \\
Entering feed pressure & net power output, permeate \% \\
Ratio of feed to draw flow rate & permeate \%, friction losses, power density \\
Ratio of feed to draw channel heights & friction losses \\
\hline
\end{tabular}

Table 5. Optimal operating and physical parameters for the parallel module alternative and the tiered module alternative for a 30 MGD plant capacity. The flow rates are reported as rates per module. The percent permeate is given for the entire system.

\begin{tabular}{|ccc|}
\hline Parameter & Modules in parallel & Tiered with seawater refill \\
\hline Feed/total flow ratio & 0.472 & 0.399 \\
Feed flow rate & $3,630 \mathrm{~m}^{3} /$ day & $4,325 \mathrm{~m}^{3} / \mathrm{day}$ \\
Draw flow rate & $4,056 \mathrm{~m}^{3} /$ day & $6,508 \mathrm{~m}^{3} / \mathrm{day}$ \\
Entering draw pressure & $203.9 \mathrm{psi}$ & $224.5 \mathrm{psi}$ \\
Entering feed pressure & $5.5 \mathrm{psi}$ & $10.4 \mathrm{psi}$ \\
Ratio of feed to draw & 0.64 & 0.47 \\
channel heights & 4834 & 3429 \\
Total number of modules & $86.25 \%$ & $94.4 \%$ \\
Percent permeate & & \\
\hline
\end{tabular}

Table 6. Power density, net power, and specific energy for the membrane and facility determined for each alternative module configuration.

\begin{tabular}{|ccc|}
\hline Parameter & Single Module & Tiered Modules \\
\hline Power density & $2.87 \mathrm{~W} / \mathrm{m}^{2}$ & $3.25 \mathrm{~W} / \mathrm{m}^{2}$ \\
Facility net power & $120 \mathrm{~kW}$ & $152 \mathrm{~kW}$ \\
Permeate specific energy & $0.38 \mathrm{kWh} / \mathrm{m}^{3}$ & $0.42 \mathrm{kWh} / \mathrm{m}^{3}$ \\
Net specific energy & $0.10 \mathrm{kWh} / \mathrm{m}^{3}$ & $0.12 \mathrm{kWh} / \mathrm{m}^{3}$ \\
\hline
\end{tabular}


Table 7. A summary of previous studies of PRO membrane modules, including the current investigation.

\begin{tabular}{|c|c|c|c|c|c|}
\hline $\begin{array}{c}\text { Feed/Draw } \\
\text { Ratio }\end{array}$ & Parameters & System & $\begin{array}{c}\text { Net } \\
\text { Power } \\
\text { Density } \\
\left(\mathrm{W} / \mathrm{m}^{2}\right)\end{array}$ & $\begin{array}{c}\text { Net } \\
\text { Specific } \\
\text { Energy } \\
\left(\mathbf{k W h} / \mathbf{m}^{3}\right)\end{array}$ & Reference \\
\hline 0.637 & $\begin{array}{c}\mathrm{A}=1.87 \mathrm{e}-12 \mathrm{~m}^{3} / \mathrm{Pa}-\mathrm{s}-\mathrm{m}^{2} \\
\mathrm{~B}=1.11 \mathrm{e}-7 \mathrm{~m}^{3} / \mathrm{s}-\mathrm{m}^{2} \\
\mathrm{~S}=0.678 \mathrm{~mm} \\
\text { Temperature }=24^{\circ} \mathrm{C}\end{array}$ & $\begin{array}{l}\text { Simulation: } \\
\text { Hollow fiber } \\
\text { membrane } \\
\text { module }\end{array}$ & 1.33 & - & [13] \\
\hline 1 & $\begin{array}{c}\mathrm{A}=11.7 \mathrm{e}-12 \mathrm{~m}^{3} / \mathrm{Pa}-\mathrm{s}-\mathrm{m}^{2} \\
\mathrm{~B}=0.4 \mathrm{e}-6 \mathrm{~m}^{3} / \mathrm{s}-\mathrm{m}^{2} \\
\mathrm{~S}=0.267 \mathrm{~mm} \\
\text { Temperature }=0^{\circ} \mathrm{C}\end{array}$ & $\begin{array}{l}\text { Simulation: } \\
\text { Commercially } \\
\text { available } \\
\text { membrane } \\
\text { module }\end{array}$ & 0.85 & 0.05 & [43] \\
\hline 0.311 & $\begin{array}{c}\mathrm{A}=0.81 \mathrm{~L} / \mathrm{m}^{2}-\mathrm{h}-\mathrm{bar}^{\mathrm{a}} \\
\mathrm{B}=0.24 \mathrm{~L} / \mathrm{m}^{2}-\mathrm{h}^{\mathrm{b}} \\
\mathrm{S}=1.04 \mathrm{~mm}^{\mathrm{c}} \\
\text { Temperature }=25^{\circ} \mathrm{C}\end{array}$ & $\begin{array}{c}\text { Experimental: } \\
\text { Prototype } 8040 \\
\text { PRO spiral } \\
\text { wound } \\
\text { membrane } \\
\text { module }\end{array}$ & $0.9^{\mathrm{d}}$ & - & [16] \\
\hline- & $\begin{array}{c}\mathrm{A}=1.42 \mathrm{e}-8 \mathrm{~m} / \mathrm{s}-\mathrm{kPa} \\
\mathrm{B}=2.41 \mathrm{e}-8 \mathrm{~m} / \mathrm{s} \\
\mathrm{S}=0.310 \mathrm{~mm} \\
\text { Temperature }=22^{\circ} \mathrm{C}\end{array}$ & $\begin{array}{c}\text { Experimental: } \\
4040 \text { spiral } \\
\text { wound TFC } \\
\text { PRO spiral } \\
\text { wound } \\
\text { membrane } \\
\text { module }\end{array}$ & $1.15^{\mathrm{d}}$ & 0.025 & [17] \\
\hline 0.665 & $\begin{array}{c}\mathrm{A}=1.23 \mathrm{e}-3 \mathrm{~m} / \text { day-kPa } \\
\mathrm{B}=2.08 \mathrm{e}-3 \mathrm{~m} / \text { day } \\
\mathrm{S}=0.310 \mathrm{~mm} \\
\text { Temperature }=18^{\circ} \mathrm{C}\end{array}$ & $\begin{array}{c}\text { Simulation: } \\
8040 \text { PRO spiral } \\
\text { wound } \\
\text { membrane } \\
\text { module }\end{array}$ & 0.83 & 0.12 & $\begin{array}{c}\text { Current } \\
\text { Study }\end{array}$ \\
\hline
\end{tabular}

${ }^{a}$ The water permeability coefficient was determined experimentally at a hydraulic pressure difference of 7.8 bar.

${ }^{\mathrm{b}}$ The salt permeability coefficient was determined experimentally at a hydraulic pressure difference of 7.8 bar.

${ }^{\mathrm{C}}$ The structural parameter was determined by Equation 21, and is the average value of the structural parameters determined at hydraulic pressure differences of 7.8, 11.7, and 15.7 bar in PRO configuration. ${ }^{d}$ The power density calculated is the power output of the membrane module and does not include parasitic loads external to the module. 


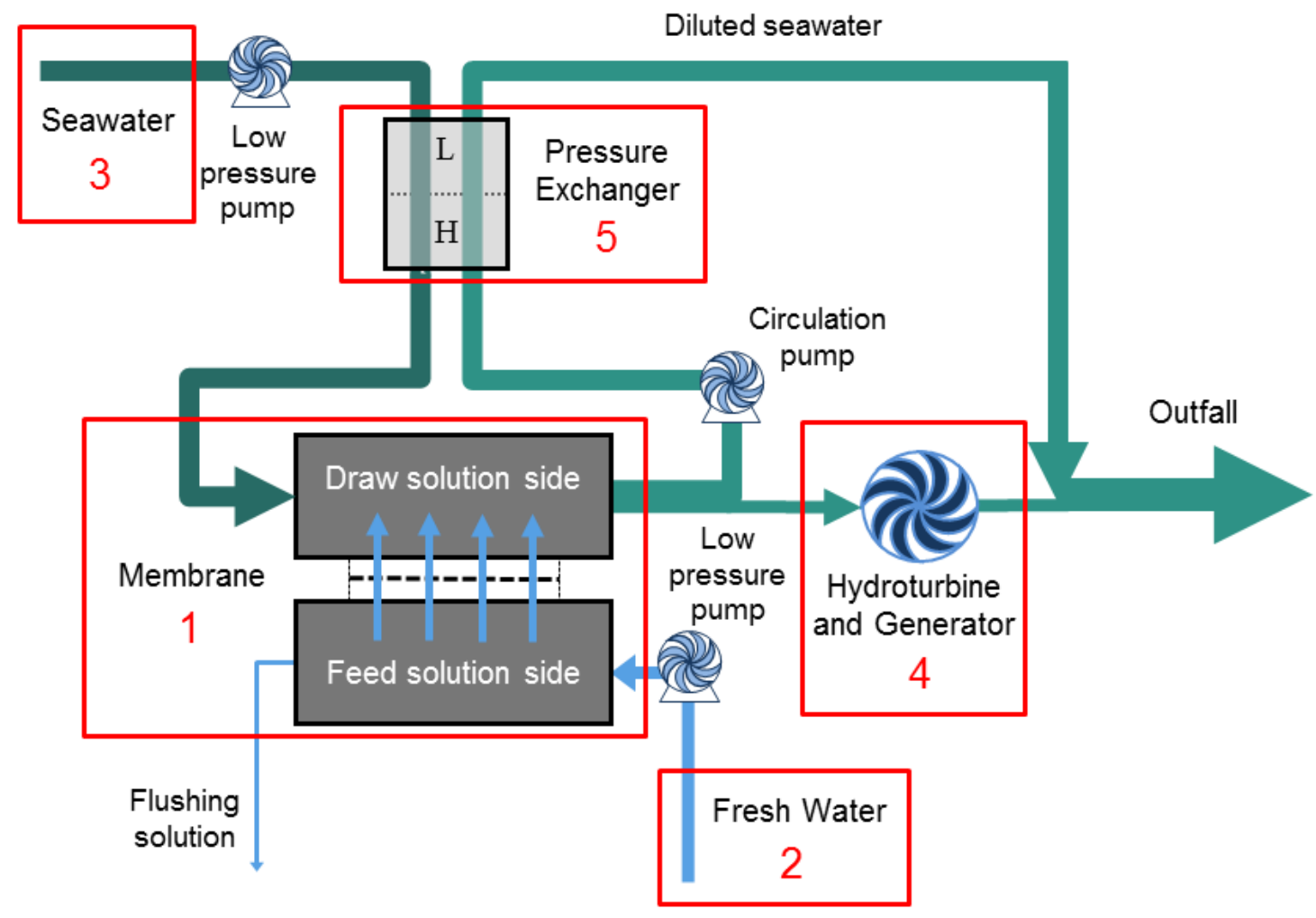

Figure 1. Designated subsystems of the entire PRO system: Subsystem 1 consists of the membrane module. Subsystem 2 and subsystem 3 consists of the freshwater and seawater pretreatment and conveyance, respectively. Subsystem 4 is the hydroturbine and generator. Subsystem 5 is the pressure exchanger, which works to conserve the pressure within the system. Adapted from [20]. 


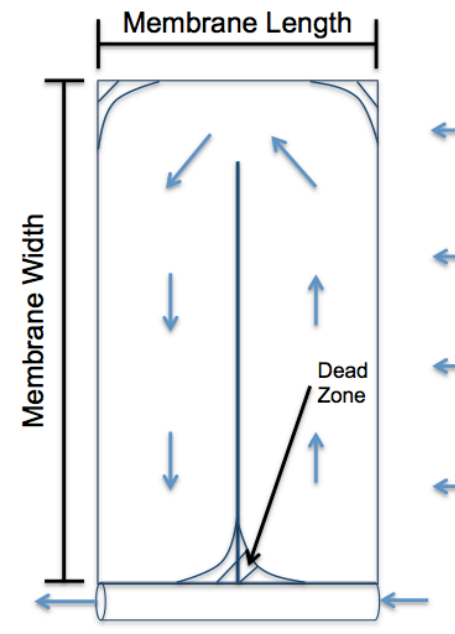

a.

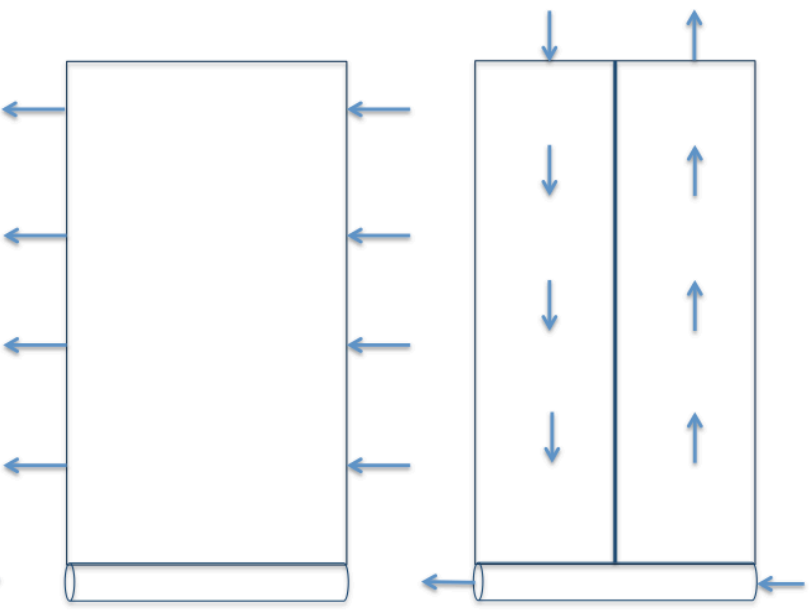

b.
C.

Figure 2. Flow paths along spiral wound membrane leaves for: a) realistic flow path configuration with 1 baffle, b) flow path assumed for the seawater (draw solution) in the simulation model, and c) fresh water (feed solution) flow path in the simulation model. 

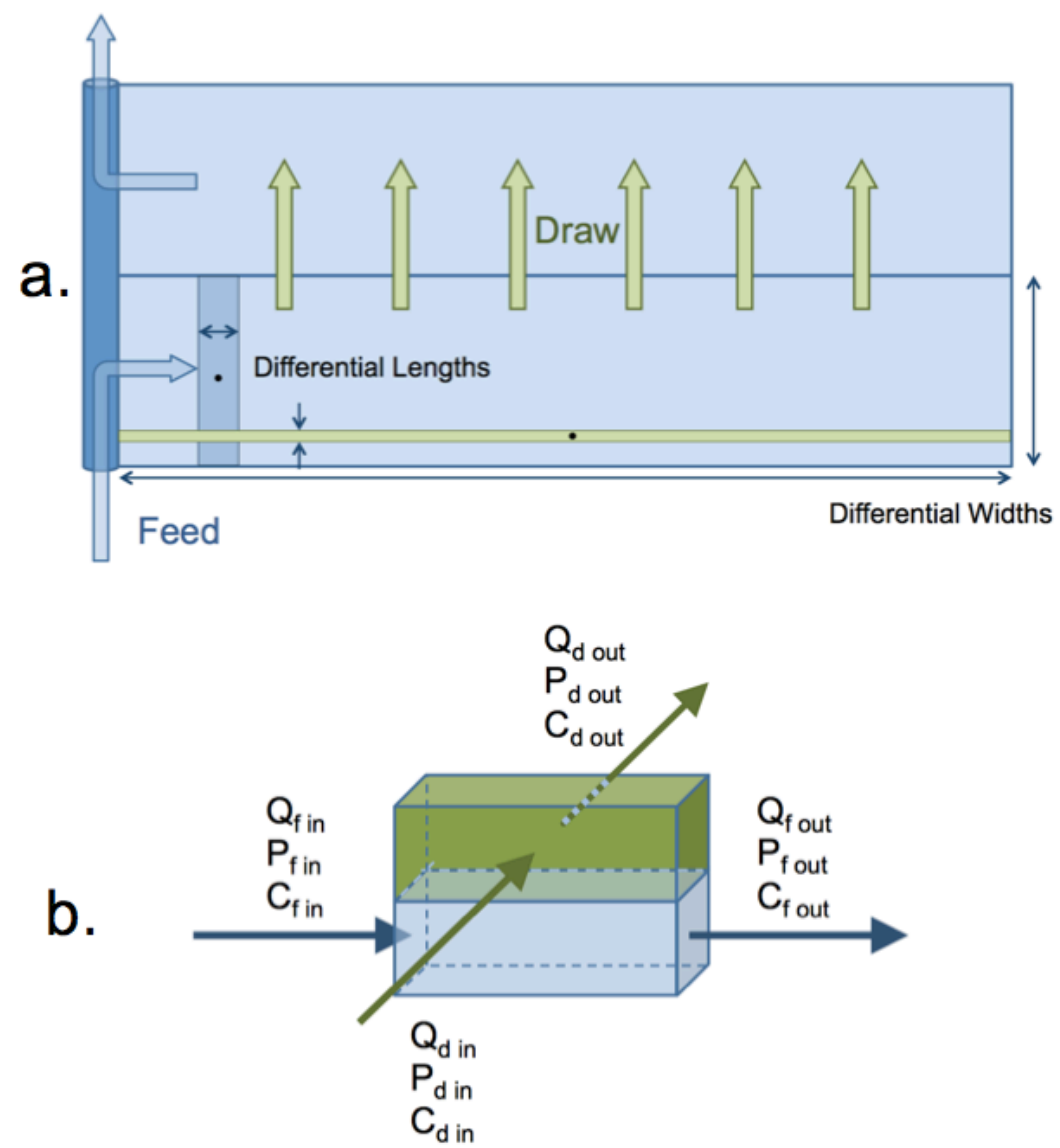

Figure 3. a) The differential areas for the feed and draw solutions. The differential area represented for the draw and feed solutions are equal; however, the differential lengths and widths are representative of their respective flow paths. This representation of the cross-flow dynamics in a spiral-wound membrane module more closely approximates the actual flow path than either co-current or counter-current approximations. b) Membrane segment of a differential width showing salt flux, water flux and entering and exiting conditions. 


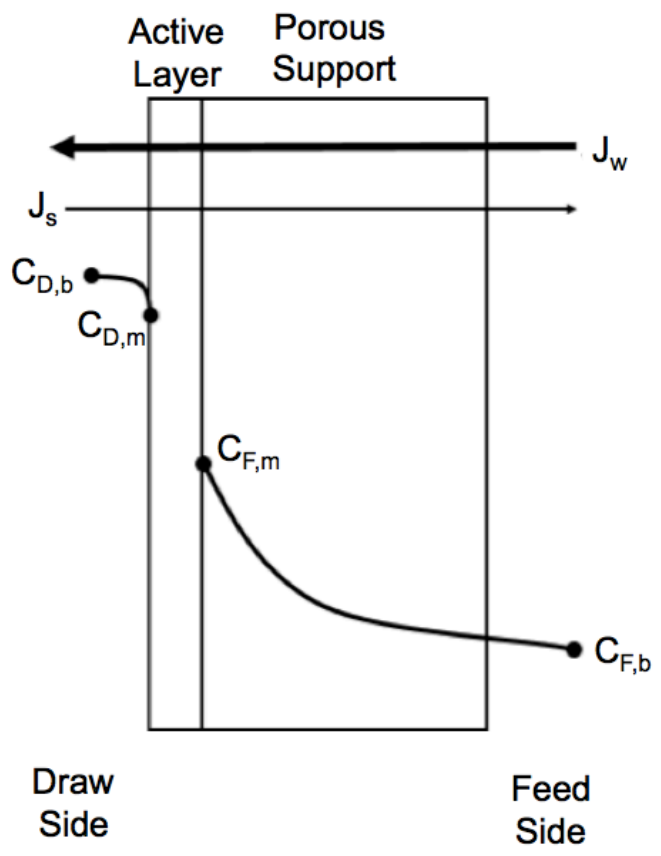

Figure 4. Schematic of the active and support layers experiencing the effects of ECP in the draw channel and ICP within the support layer. ECP in the feed channel is neglected [24]. 


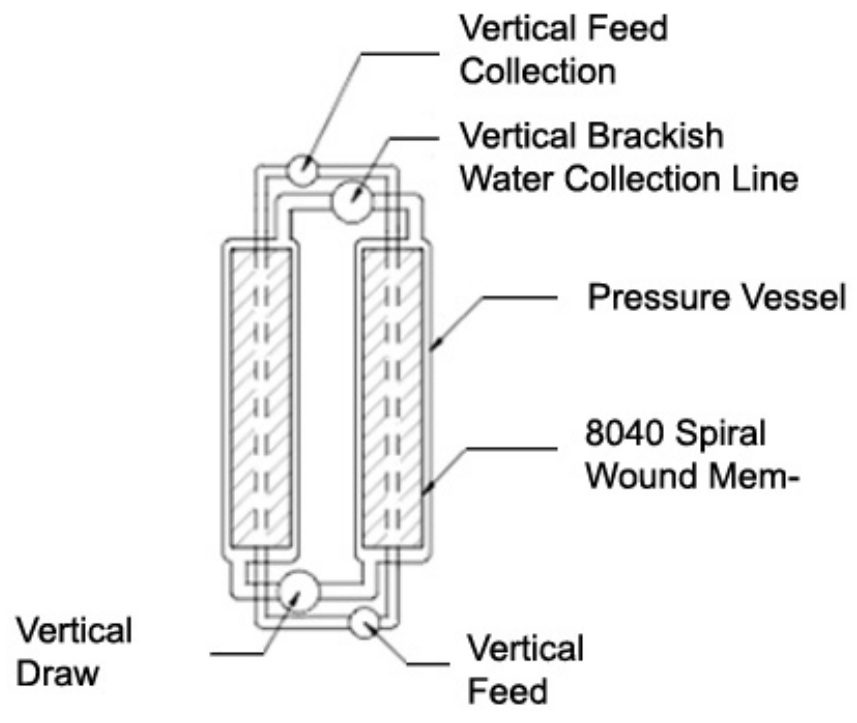

Figure 5. Schematic of the parallel module configuration with one membrane in one pressure vessel 


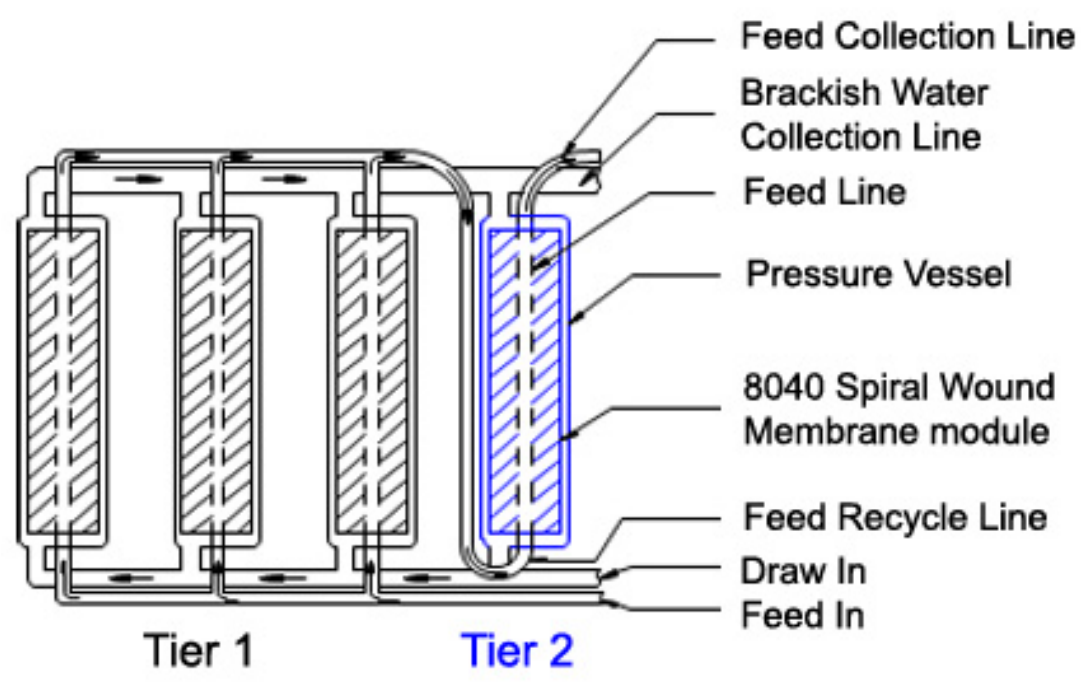

Figure 6. Schematic of the tiered module configuration with three membranes in the first tier, each within their own respective pressure vessels, and one membrane in the second tier. Draw solution is in parallel while the feed solution is fed into the first tier and then into the second one. 


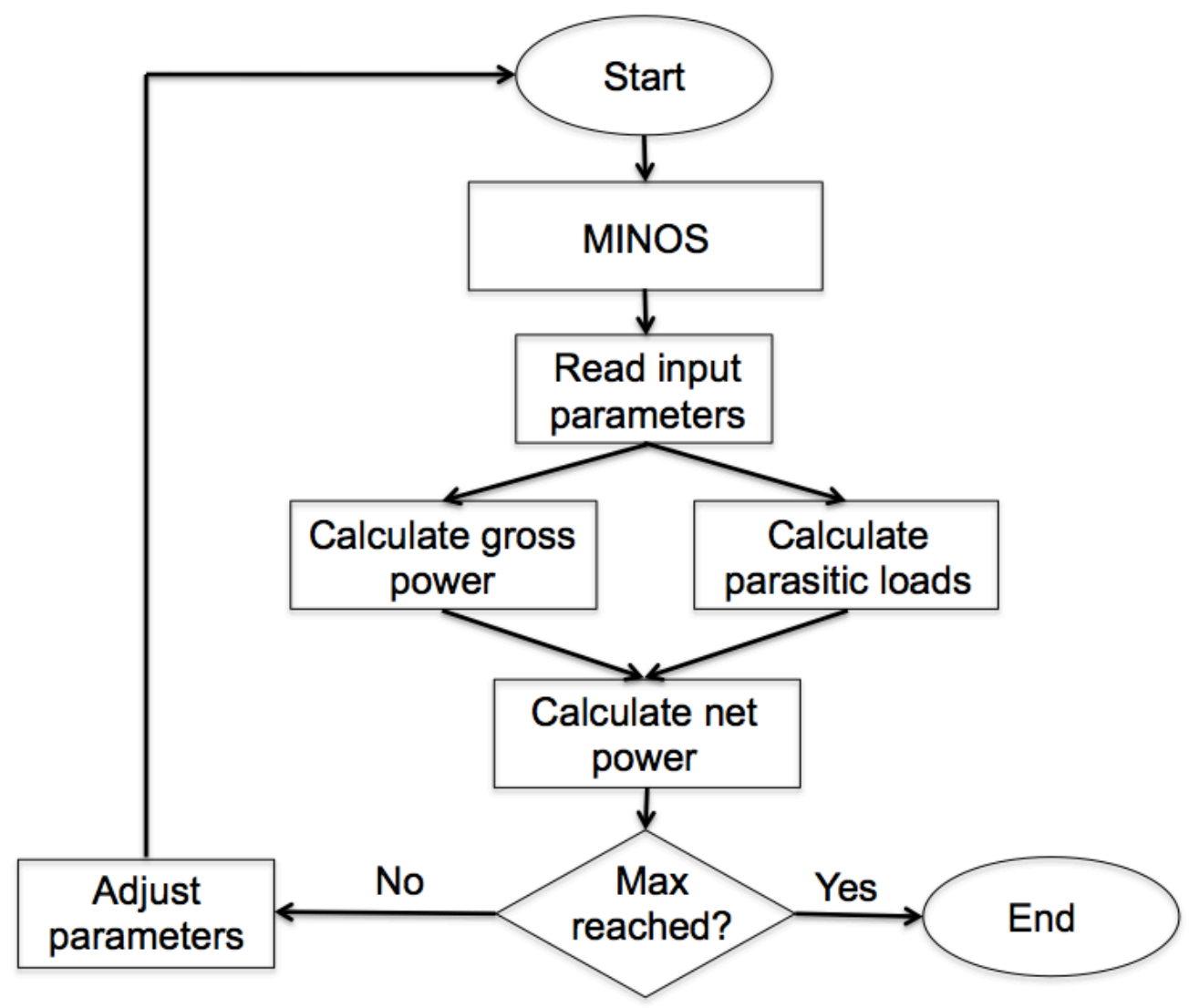

Figure 7. Flowchart for the LSO model. MINOS first reads the input parameters into the simulation model, called FluxSIM in the flowchart. The simulation model calculates the gross power produced and the energy requirement of the fresh water and seawater pretreatment. The overall net power is then calculated as the difference of the two, and the input parameters are adjusted. This process iterates until a maximum net power is reached. 


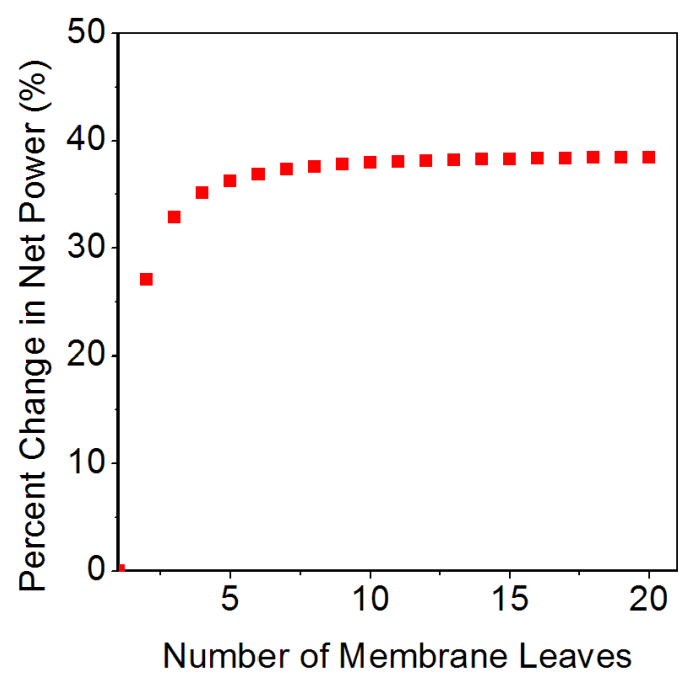

Figure 8. Percent increase in net power as function of increasing the number of membrane leaves within the membrane module. Percent change is calculated by dividing the net power achieved with different leaves per module by the net power achieved by one leaf per module. 


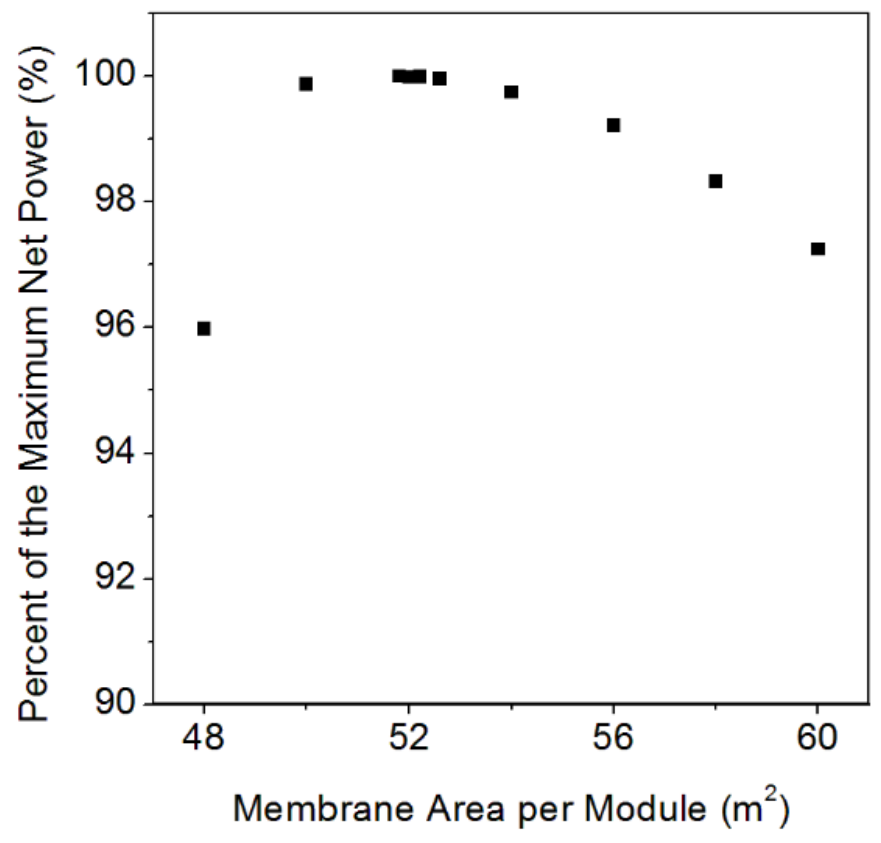

Figure 9. Percent of the maximum net power as a function of membrane area. Maximum net power is determined by the LSO. The optimal membrane area is approximately $53 \mathrm{~m}^{2}$ per module. 

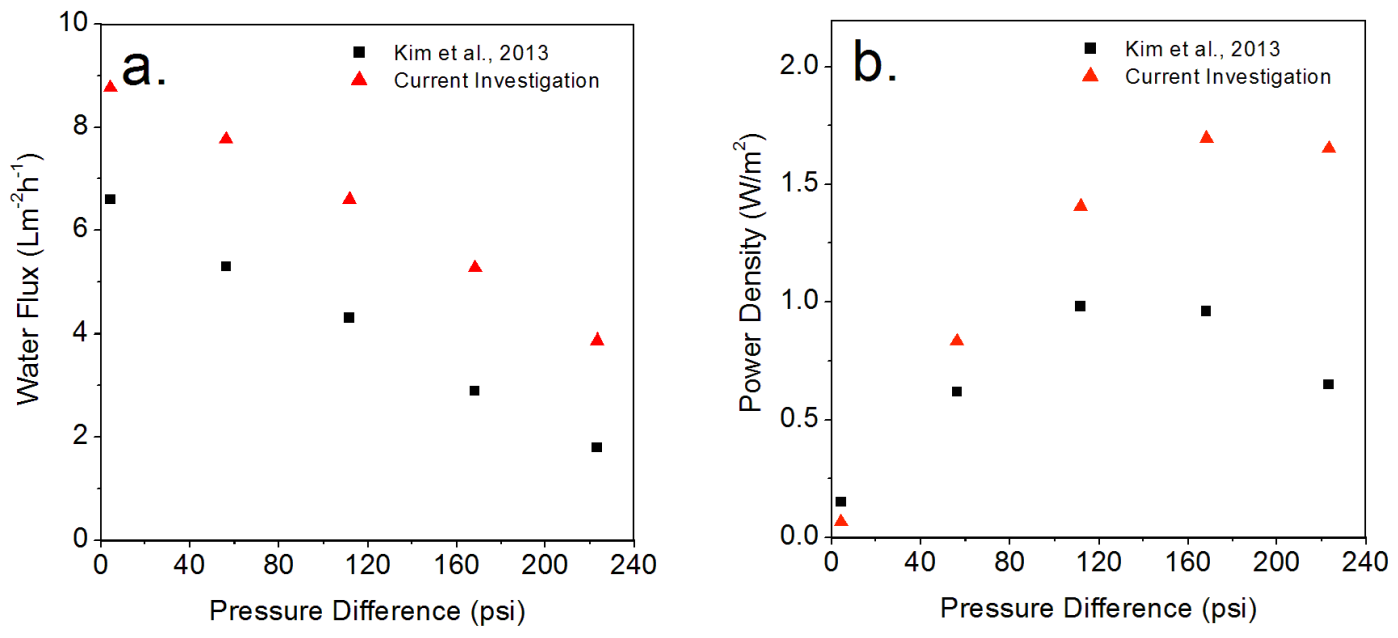

Figure 10. Simulated water flux (a.) and power density (b.) versus hydraulic pressure, compared to the experimental results published by Kim and coworkers [16]. The feed and draw flow rates are 7 LPM and 22.5 LPM, respectively. The draw solution was $35 \mathrm{~g} / \mathrm{L}$ and the feed solution was $0.5 \mathrm{~g} / \mathrm{L}$ for all simulations. 
Ideal Maximum Specific Energy

Maximum Specific Energy at Fixed Pressure

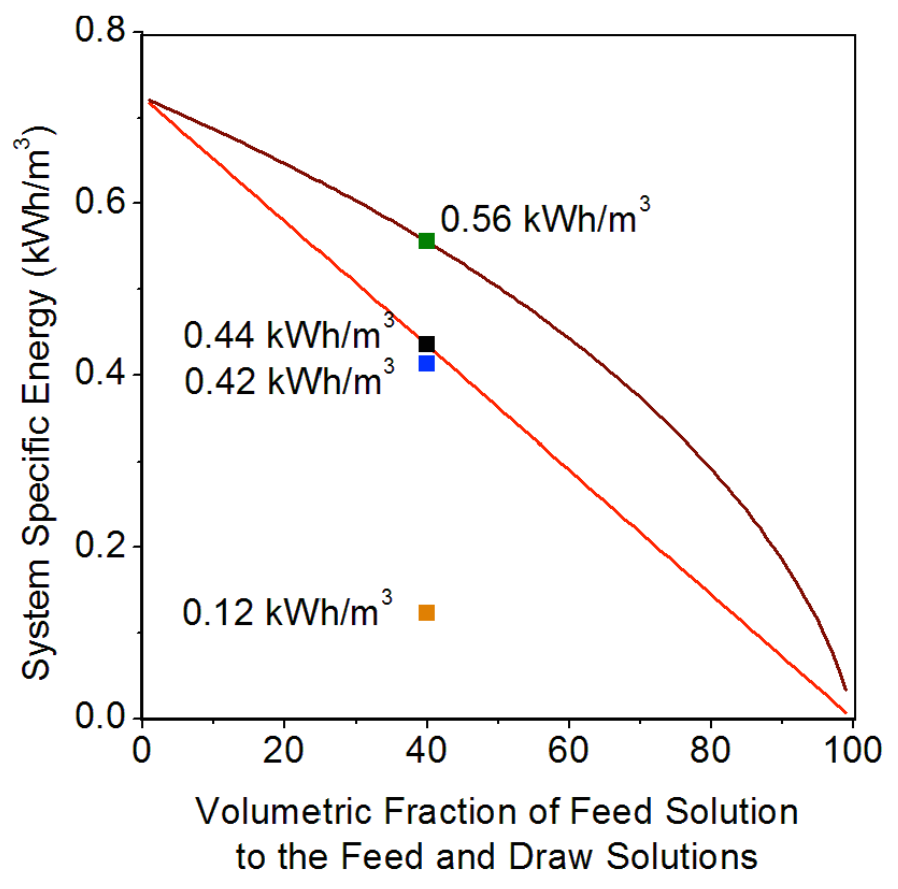

Figure 11. System specific energy as function of the volumetric fraction of the feed solution to both the feed and draw solutions. The curved line represents the Gibbs free energy of mixing, and the straight line represents the maximum extractable work of the PRO process at a fixed pressure. The Gibbs free energy of mixing at $40 \%$ is $0.56 \mathrm{kWh} / \mathrm{m}^{3}$, but due to PRO being a fixed pressure process in application, the maximum extractable work is $0.44 \mathrm{kWh} / \mathrm{m}^{3}$. Accounting for friction and energy losses in a non-ideal PRO process yields a specific energy of $0.42 \mathrm{kWh} / \mathrm{m}^{3}$ in the tiered module configuration. Once the parasitic loads of the system are taken into account, the system specific energy drops to $0.12 \mathrm{kWh} / \mathrm{m}^{3}$. 


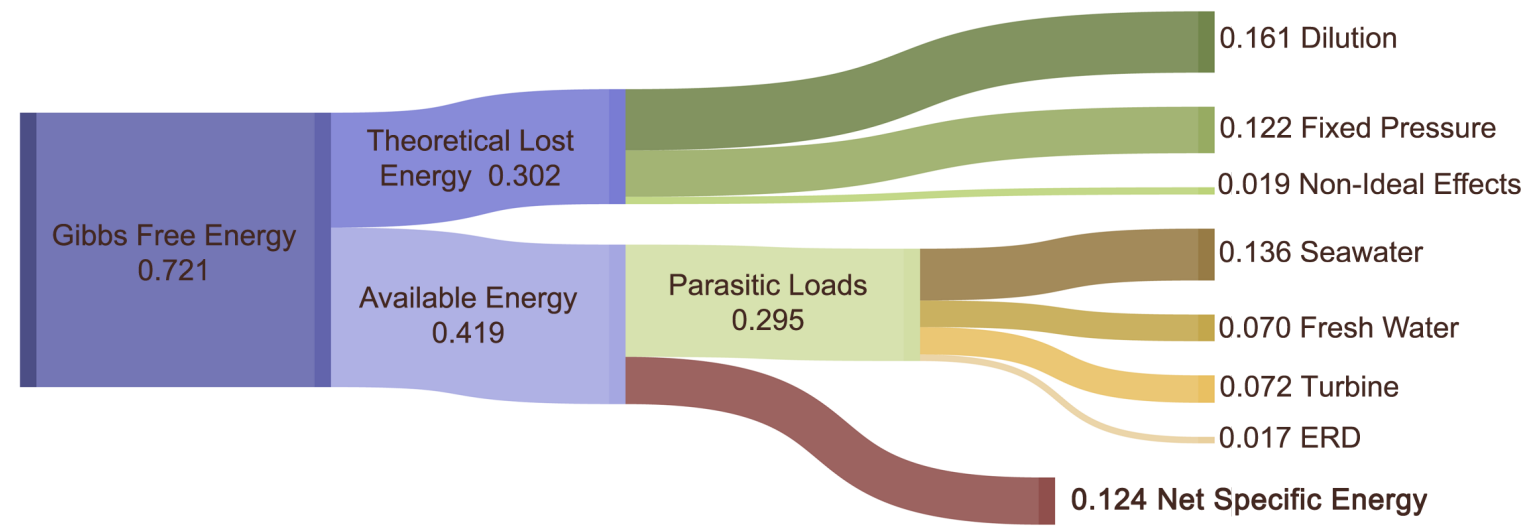

Figure 12. Sankey diagram of the resource utilization of a river-to-sea PRO facility. Gibbs free energy of mixing at $18^{\circ} \mathrm{C}$ and theoretical and practical energy losses are normalized to the permeate volume. The theoretical energy losses are the dilution effect of mixing 2 parts fresh water with 3 parts seawater, the fixed pressure loss in the tiered configuration, non-ideal osmosis, and the feed channel friction losses. The parasitic loads of the seawater, freshwater, turbine and ERD subsystems are displayed, and they reduce the available net specific energy to $0.124 \mathrm{kWh} / \mathrm{m}^{3}$. The seawater and freshwater parasitic loads include both the pretreatment costs as well as the pumping efficiency of the booster pump necessary to supply the modules with water at the operating pressure. The available net specific energy is approximately $17 \%$ of the Gibbs free energy of mixing freshwater with seawater. The Sankey diagram was produced with the open source tool SankeyMATIC [39]. 


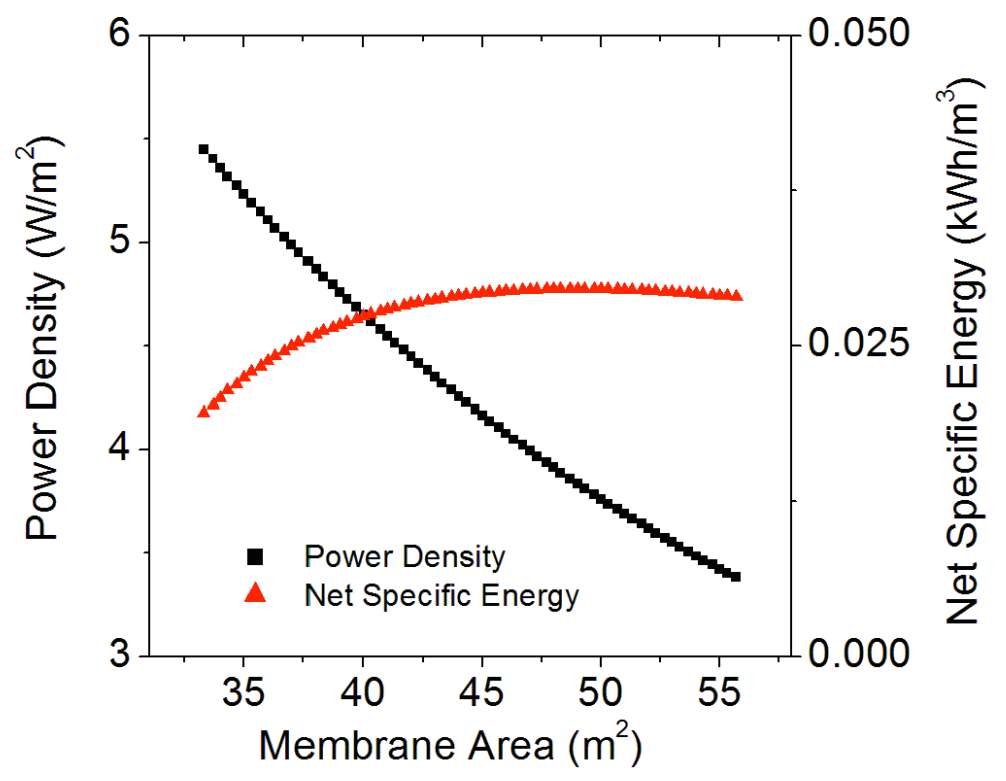

Figure 13. Power density of the membrane and the net specific energy as function of the membrane area per module. 

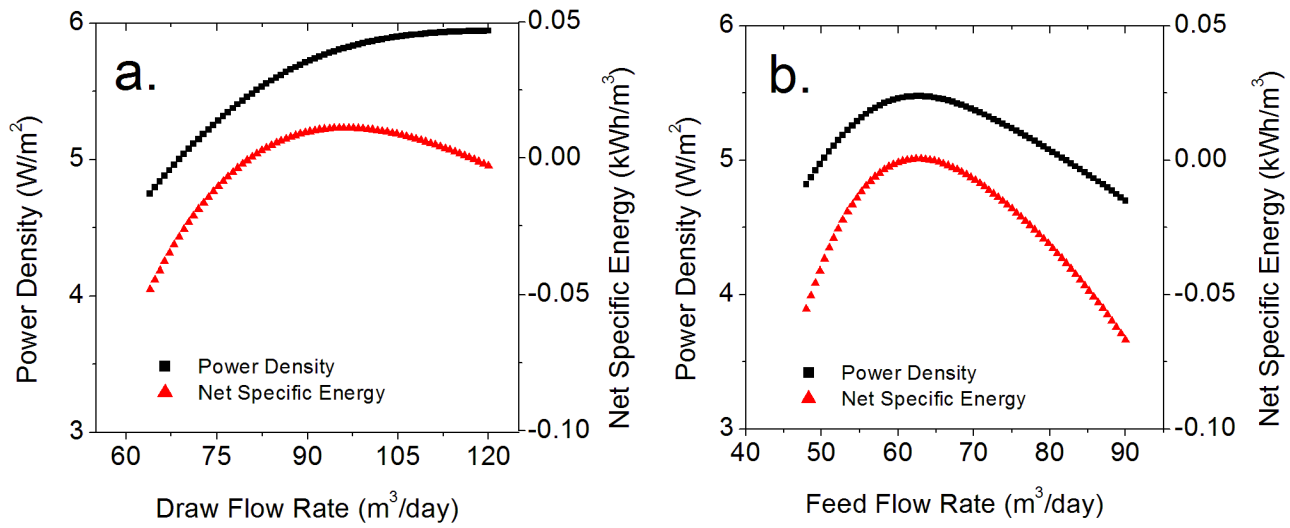

Figure 14. Power density and net specific energy as function of the draw (a) and feed (b) solution flow rate. 

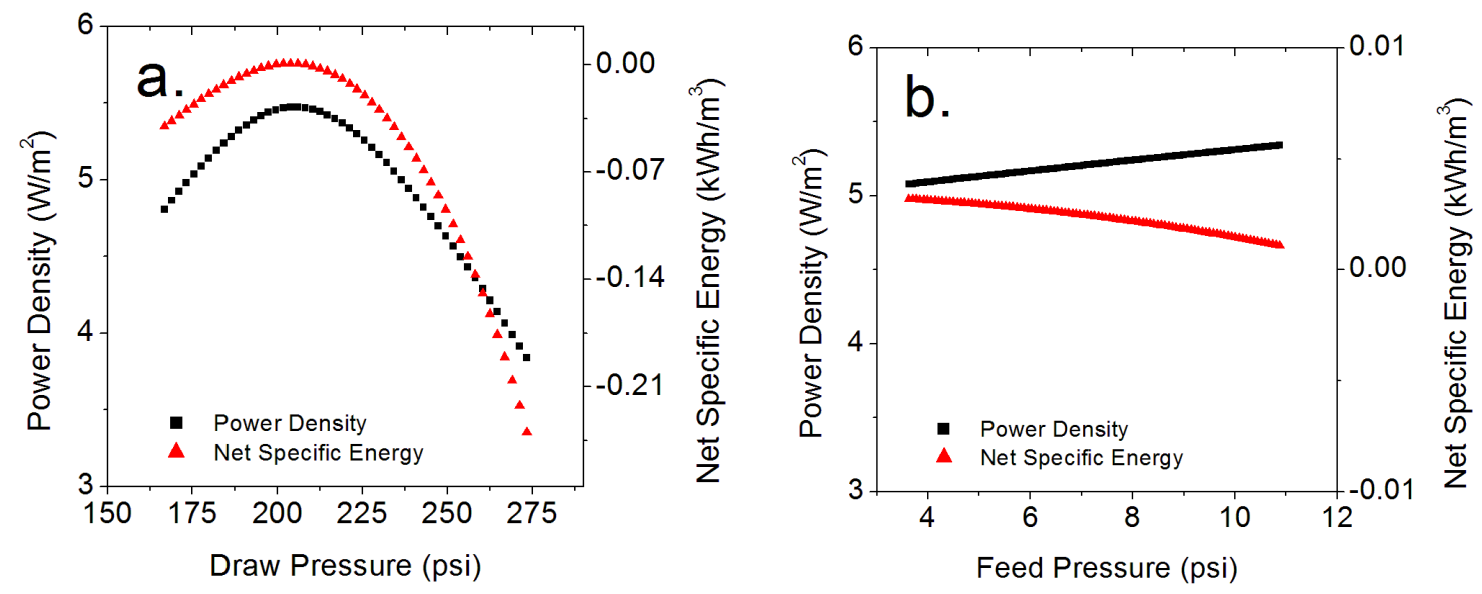

Figures 15. Power density and net specific energy as function of the applied pressure on (a) the draw and (b) feed solutions. 
Graphical abstract

\section{Pressure Retarded Osmosis Energy Efficiency}

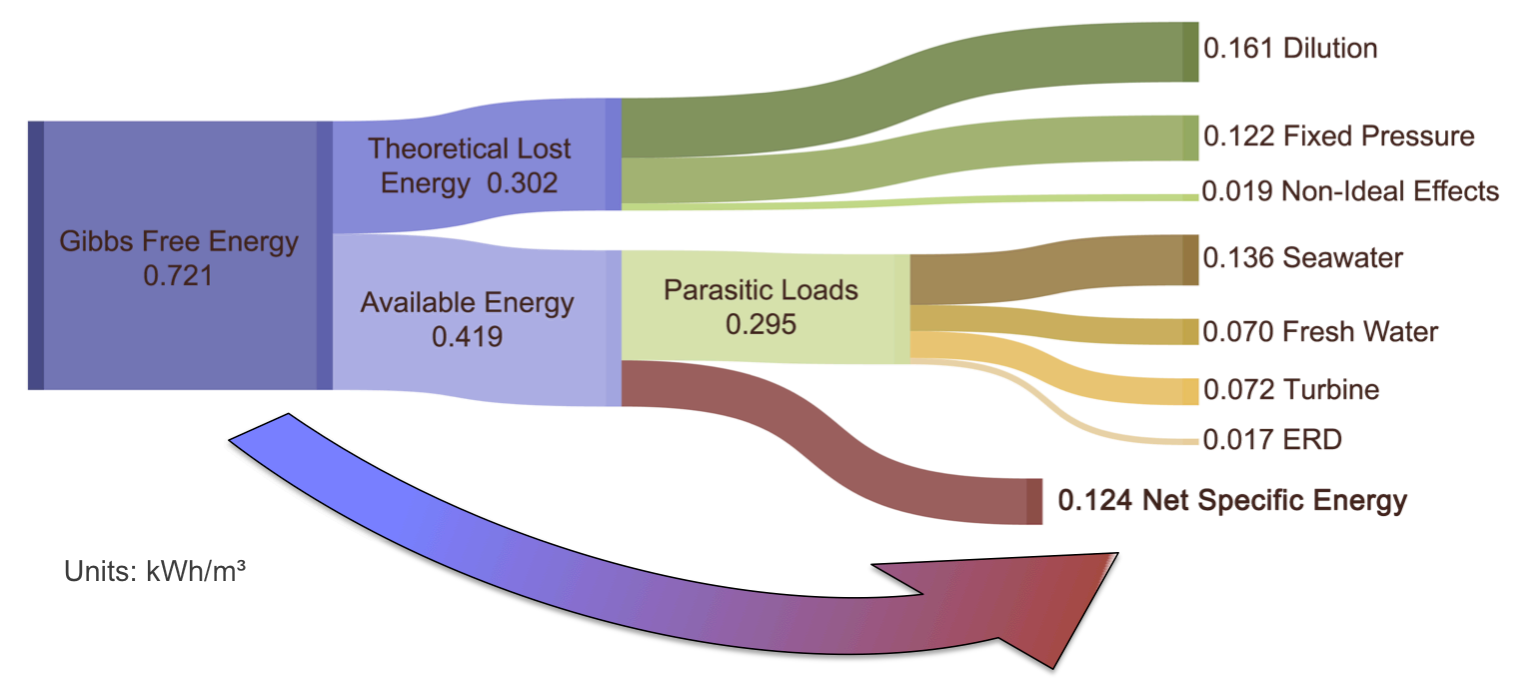

